\title{
[1
}

TI 2019-037/V

Tinbergen Institute Discussion Paper

\section{The impact of WTO accession on Chinese firms' product and labor market power}

Sabien Dobbelaere ${ }^{1,2,3}$

Quint Wiersma ${ }^{1,2}$

\footnotetext{
${ }^{1}$ Vrije Universiteit Amsterdam

2 Tinbergen Institute

${ }^{3}$ Institute of Labor Economics (IZA)
} 
Tinbergen Institute is the graduate school and research institute in economics of Erasmus University Rotterdam, the University of Amsterdam and VU University Amsterdam.

Contact: discussionpapers@tinbergen.nl

More TI discussion papers can be downloaded at https://www.tinbergen.nl

Tinbergen Institute has two locations:

Tinbergen Institute Amsterdam

Gustav Mahlerplein 117

1082 MS Amsterdam

The Netherlands

Tel.: + 31(0)205984580

Tinbergen Institute Rotterdam

Burg. Oudlaan 50

3062 PA Rotterdam

The Netherlands

Tel.: +31(0)10408 8900 


\title{
The impact of WTO accession on \\ Chinese firms' product and labor market power
}

\author{
Sabien Dobbelaere ${ }^{a, b, c} \quad$ Quint Wiersma ${ }^{a, b}$ \\ a Vrije Universiteit Amsterdam \\ $b$ Tinbergen Institute \\ ${ }^{c}$ Institute of Labor Economics (IZA)
}

June, 2019

\begin{abstract}
This paper examines the impact of WTO membership on the extensive and intensive margins of product and labor market power of Chinese manufacturing firms during the period 19992006. We first identify a firm's regime of competitiveness, corresponding to a combination of a product market setting and a labor market setting, at any point in time through implementing the testing procedure of Kodde and Palm (1986), the distance test. Our descriptive differencesin-differences analysis shows that an industry's dominant regime of competitiveness is stable over time. Exploiting variation in input and output tariff reductions after WTO accession across industries, we then show that on the extensive margin, reducing tariffs on intermediate inputs decreases the likelihood of shifting firms away from an imperfectly competitive labor market setting where the marginal employee is paid a real wage either above or below her marginal product (i.e. wage markup or markdown). In contrast, falling tariffs on final goods increases the likelihood of switching firms away from setting wage markdowns. On the intensive margin, trade liberalization via input tariff reductions is found to increase a firm's price-cost markup but to decrease the degree of wage-setting power that a firm possesses. Such joint responses of firms' pricing behavior to trade policy changes are important for understanding increased inter-firm wage disparities.
\end{abstract}

Keywords: Rent sharing, monopsony, price-cost markups, trade liberalization, firm panel data, hypothesis testing, inequality restrictions.

JEL classification: C12, C23, C63, F61, J30, L20. 


\section{Introduction}

Since the beginning of socio-economic reforms in 1978, China's transformation from a state socialist redistributive economy into an increasingly market-driven economy has led to substantial efficiency gains and rapid economic growth (Maddison et al., 1998; Fan et al., 2003). The role of market forces in domestic and international economic relations has become large by any standards, with the process of change having been accelerated by World Trade Organization (WTO) entry (OECD, 2005; Zhang and Tan, 2007; Holz, 2009).

China's transition from a planned allocation of labor in state-sector jobs to a labor market has been stimulated by economic globalization. Incentive mechanism and allocation system reforms, such as eliminating a series of hukou-related institutional barriers deterring labor mobility, reducing the role of state enterprises as employers and as a source of social insurance, and granting management power to determine wages within enterprises, have undoubtedly improved technical and allocative efficiencies (Cai et al., 2008). Yet, due to the partial, incremental and uneven nature of labor market reforms, numerous studies conclude that there is still significant segmentation in the labor market (Meng, 2000; Knight and Shi, 2005; Zhang and Tan, 2007; Xie and Wu, 2008; Huang, 2017). As such, wage differences across firms are not ironed out by labor market competition. Knight and Shi (2005) and Nee and Opper (2012) provide evidence of the growing importance of profitability in wage determination, which has contributed to widening wage inequality. Duan and Martins (2018) find wage-profit elasticities ranging between 0.03 and 0.06, even though many formal labour market institutions are still at an early stage of development.

Despite the implementation of structural reforms, there still exist large inefficiencies in the allocation of factors of production (Gong and Xie, 2006; Brandt and Zhu, 2010; Kamal and Lovely, 2012; World Bank, 2013). Brandt et al. (2013) document that factor market distortions have increased significantly since 1997, reducing aggregate non-agricultural total factor productivity growth by half a percent a year. In spite of such overwhelming evidence on factor market distortions, no empirical study has so far estimated the impact of WTO entry on price distortions in product as well as labor markets. ${ }^{1}$

We contribute to the empirical international trade literature on establishing causal evidence of trade liberalization on firms' product and labor market power using actual liberalization periods. ${ }^{2}$ Such investigation is well justified for several reasons. First, recent theoretical heterogeneous-firms approaches to trade and wage inequality all draw on imperfect labor markets and consider rent sharing to be the key mechanism through which trade-induced variation in rents is transmitted

\footnotetext{
${ }^{1}$ The effect of WTO membership on the degree of liberalization, firm performance (productivity and price-cost markups) and welfare gains has been extensively analyzed (see e.g. Lardy (2004), Brandt et al. (2012), Di Giovanni et al. (2014), and Brandt et al. (2017)).

${ }^{2}$ Trade economists have a long tradition of investigating the impact of globalization on firms' price-cost markups and have provided evidence on such procompetitive effect using actual trade liberalization episodes (see Tybout (2008), De Loecker and Goldberg (2014), and De Loecker and Van Biesebroeck (2016) for surveys).
} 
to variation in wages. ${ }^{3}$ Second, disentangling the impact of trade liberalization on product versus labor market power matters a lot for policy concerned with allocative efficiency, (wage and consumption) inequality, welfare losses, and the falling labor share in national income. ${ }^{4}$ As such, our analysis sheds light on whether either market power on the supply side of labor or market power on the demand side of labor is predominantly responsible for distorting factor prices and whether the balance of power has shifted after WTO entry.

We first examine potential shifts in Chinese firms' regimes characterizing the type of competition prevailing in product and labor markets during one of the most recent trade liberalization episodes, i.e. the years surrounding China's accession into the WTO in 2001. We use a panel of 57,577 manufacturing firms located in the three most important economic regions during the period 19992006, constructed from annual surveys conducted by the National Bureau of Statistics (NBS). Following Dobbelaere and Mairesse (2013), we consider six possible regimes of competitiveness $R \in$ $\Re=\{P C-P R, I C-P R, P C-E B, I C-E B, P C-M O, I C-M O\}$, each corresponding to a combination of the type of competition prevailing in the product market or product market setting, and the type of competition prevailing in the labor market or labor market setting. The product market setting (denoted $P M S$ ) is either perfect competition $(P C)$ or imperfect competition $(I C)$. This simple dichotomy is based on the price-cost markup, i.e. either no market power (price-cost markup equal to one) or market power (price-cost markup exceeding one). The labor market setting (denoted $L M S)$ is either perfect competition or right-to-manage bargaining $(P R)$, efficient bargaining $(E B)$ or monopsony $(M O)$. Intuitively, a firm in which the marginal employee is paid a real wage $(i)$ equal to her marginal product is characterized by $L M S=P R,(i i)$ exceeding her marginal product (wage markup) is characterized by $L M S=E B$, or (iii) lower than her marginal product (wage markdown) is characterized by $L M S=M O$.

The characterization of competitiveness regimes is based on identifying gaps between the marginal products of two variable inputs of production (labor and intermediate inputs) and their marginal costs, which is related to allocative inefficiencies in terms of their impact on aggregate productivity growth as shown by Petrin and Sivadasan (2013). The identification of a firm's competitiveness regime at any point in time is based on implementing the testing procedure of Kodde and Palm (1986), the distance test, which is capable of handling equality and inequality constraints under the null as well as the alternative. Once a firm's regime is determined, we are able to quantify the degree of market power in product and labor markets. As noted above, our model consistent measure of product market power is a firm's price-cost markup for firms characterized by $P M S=I C$. Our model consistent measure of labor market power is either the part of economic rents going to the workers or the workers' bargaining power during worker-firm negotiations for firms characterized by $L M S=E B$, or the wage elasticity of a firm's labor supply reflecting the wage setting power that a firm possesses for firms characterized by $L M S=M O$.

\footnotetext{
${ }^{3}$ The various heterogeneous-firms approaches differ in terms of the rent-sharing mechanism between workers and firms. For example, one approach focuses on search and matching frictions such that ex-post bargaining over the surplus of production can potentially induce wages to vary with revenue across firms (Davidson et al., 2008; Helpman et al., 2010; Felbermayr et al., 2011; Fajgelbaum, 2013; Coşar et al., 2016), while another approach considers decentralized collective bargaining as generating inter-firm wage dispersion (Montagna and Nocco, 2013).

${ }^{4}$ Brooks et al. (2019) show evidence of the importance of firms' wage-setting power in explaining a falling labor share in China over the period 1999-2017. Berger et al. (2019) document substantial welfare losses from firms' labor market (monopsony) power using US Census micro data.
} 
We then examine whether China's WTO membership has affected the extensive and intensive margins of product and labor market power of Chinese firms. To serve this purpose, we exploit variation in input and output tariff cuts after WTO accession across industries, following Lu and Yu (2015) and Brandt et al. (2017). The extensive margin analysis identifies the impact of trade liberalization on the likelihood of switching away from an imperfectly competitive product/labor market setting. The intensive margin analysis estimates the effect of reducing input and output tariffs on the degree of product/labor market power, conditional on being characterized by a particular product/labor market setting.

Four main findings emerge. First, the distance test is conclusive in identifying a firm's regime of competitiveness at any point in time in $56 \%$ of the cases. $72 \%$ of the inconclusive cases arises due to inconclusiveness between two regimes, which we interpret as mild inconclusiveness. We observe large heterogeneity across industries in terms of the level as well as the composition of the inconclusiveness. This inconclusiveness does not seem to be driven by a transition effect following WTO entry. Rather, the key driving force is inconclusiveness of the product market setting, which in turn is strongly related to the size of the industry.

Second, aggregating firm-year weighted frequencies of occurrence of competitiveness regimes at the industry level shows that the prevailing regimes vary across industries. The dominant regime at the industry level during the observed period is one of imperfect competition in the product market and efficient bargaining in the labor market, which is consistent with recent evidence on the role of workers' bargaining power in shaping the wage distribution in China over the period 2000-2007. Our descriptive analysis, based on computing differences-in-differences in weighted frequency of occurrence of each regime compared to the dominant regime of competitiveness at the industry level before and after WTO accession, reveals that an industry's dominant regime is stable over time.

Third, our extensive margin results show that trade liberalization via tariff reductions affects the likelihood that firms shift away from an imperfectly competitive labor market setting. The importance and direction of the impact depends on the mechanism that ties firm wages to firm performance and on the type of tariffs. More specifically, input tariff cuts, which might increase technical efficiency through access to lower-cost and superior intermediate products, decrease the probability of moving away from a labor market setting with either a wage markup $(E B)$ or a wage markdown $(M O)$, with the largest impact found on the latter. Contrary to this intermediate input channel of trade, we find that falling output tariffs, which decrease domestic output prices and might decrease $\mathrm{X}$-inefficiencies through reducing managerial slack and changing organizational structure, increase the likelihood that firms shift away from setting wages lower than the marginal revenue product of labor $(M O)$.

Fourth, our intensive margin results provide evidence of trade liberalization in intermediate-inputs industries having affected the degree of firms' product versus labor market power differently. More specifically, reducing tariffs on intermediate inputs increases a firm's price-cost markup (conditional on being characterized by imperfect competition in the product market), but decreases the degree of wage-setting power that a firm possesses (conditional on being characterized by monopsony). 
We view the joint responses of firms' pricing behavior in product and labor markets to trade policy changes as an important step towards understanding the distributional consequences of trade shocks and the underlying drivers of increased inter-firm wage disparities.

The outline of the article is as follows. Section 2 presents the main ingredients of the theoretical structural productivity model with imperfect product and labor markets. Section 3 discusses the econometric model. Section 4 presents the classification and testing procedures to identify a firm's regime of competitiveness at any point in time. Section 5 presents the Chinese firm panel data. Section 6 reports the outcome of the testing procedure. Sections 7 and 8 document the impact of WTO membership on the extensive and intensive margin of product and labor market power, respectively. Section 9 concludes.

\section{Theoretical structural model with imperfect product and labor markets}

A firm $i$ at time $t$ produces output using the following production technology:

$$
Q_{i t}=Q_{i t}\left(N_{i t}, M_{i t}, K_{i t}\right)
$$

with $\left(N_{i t}, M_{i t}\right)$ a vector of static inputs in production free of adjustment costs (labor and intermediate inputs) and $K_{i t}$ capital treated as a dynamic input in production (predetermined in the short run).

We assume that $(i) Q_{i t}(\cdot)$ is continuous and twice differentiable with respect to its arguments, (ii) a firm takes the input price of materials as given, (iii) firms produce in a homogeneous good industry and compete in quantities (play Cournot), ${ }^{5}$ and (iv) producers active in the market are maximizing short-run profits.

Let us turn to the oligopolistic firm's short-run profit maximization problem. Firm $i$ 's short-run profits, $\pi_{i t}$, are given by:

$$
\pi_{i t}=R_{i t}-w_{i t} N_{i t}-j_{i t} M_{i t}
$$

with $R_{i t}=P_{t} Q_{i t}$ an increasing and concave revenue function, $P_{t}$ the price of the homogenous good at time $t$, and $w_{i t}$ and $j_{i t}$ the firm's input prices for $N$ and $M$, respectively, at time $t$.

Firm $i$ must choose the optimal quantity of output and the optimal demand for intermediate inputs and labor. The optimal output choice $Q_{i t}$ satisfies the following first-order condition:

$$
\frac{P_{t}}{\left(C_{Q}\right)_{i t}}=\left(1+\frac{s_{i t}}{\eta_{t}}\right)^{-1}=\mu_{i t},
$$

with $\left(C_{Q}\right)_{i t}$ the marginal cost of production, $s_{i t}=\frac{Q_{i t}}{Q_{t}}$ the market share of firm $i, \eta_{t}=\frac{\partial Q_{t}}{\partial P_{t}} \frac{P_{t}}{Q_{t}}$ the own-price elasticity of industry demand, and $\mu_{i t}$ firm $i$ 's price-cost markup. Under Cournot competition, differences in price-cost markups across firms are generated by differences in productivity and market structure $\left(s_{i t}, \eta_{t}\right)$.

\footnotetext{
${ }^{5}$ This assumption is consistent with only observing domestic industry-wide output price indices (defined at the 4-digit level, though, see Section 5) and not firm-specific output prices.
} 
The first-order condition for the optimal choice of intermediate inputs is given by setting the marginal revenue product of intermediate inputs equal to the price of intermediate inputs:

$$
\left(Q_{M}\right)_{i t}=\frac{j_{i t}}{P_{t}}\left(1+\frac{s_{i t}}{\eta_{t}}\right)^{-1}
$$

Inserting Eq. (3) in Eq. (4) and multiplying both sides by $\frac{M_{i t}}{Q_{i t}}$ yields:

$$
\left(\varepsilon_{M}^{Q}\right)_{i t}=\mu_{i t} \alpha_{i t}^{M}
$$

From Eq. (5), it follows that profit maximization implies that optimal demand for intermediate inputs is satisfied when a firm equalizes the output elasticity with respect to intermediate inputs, denoted by $\left(\varepsilon_{M}^{Q}\right)_{i t}$, to the price-cost markup $\mu_{i t}$ multiplied by the share of intermediate input expenditure in total sales, denoted by $\alpha_{i t}^{M}=\frac{j_{i t} M_{i t}}{P_{t} Q_{i t}}$.

Firm $i$ 's optimal demand for labor depends on the characteristics of its labor market. We distinguish three labor market settings $(L M S)$ : perfect competition or right-to-manage bargaining $(P R)$, strongly efficient bargaining $(E B)$ and static partial equilibrium monopsony $(M O)$. For details, we refer to Dobbelaere and Mairesse (2013).

Under $P R$, labor is unilaterally determined by firm $i$ from short-run profit maximization, which implies the following first-order condition:

$$
\left(\varepsilon_{N}^{Q}\right)_{i t}=\mu_{i t} \alpha_{i t}^{N}
$$

Under $E B$, the firm and its workers negotiate simultaneously over wages and employment in order to maximize the joint surplus of their economic activity. An efficient wage-employment pair is obtained by maximizing a generalized Nash product (the product of the weighted net gains to the firm and its workers), implying the following first-order condition for labor:

$$
\left(\varepsilon_{N}^{Q}\right)_{i t}=\mu_{i t} \alpha_{i t}^{N}-\mu_{i t} \gamma_{i t}\left(1-\alpha_{i t}^{N}-\alpha_{i t}^{M}\right),
$$

with $\gamma_{i t}=\frac{\phi_{i t}}{1-\phi_{i t}}$ the relative extent of rent sharing and $\phi_{i t}$ the part of economic rents going to the workers or the degree of workers' bargaining power during worker-firm negotiations.

Under $M O$, firm $i$ faces a labor supply $N(w)$, which is an increasing function of the wage $w$. Short-run profit maximization implies the following first-order condition for labor:

$$
\left(\varepsilon_{N}^{Q}\right)_{i t}=\mu_{i t} \alpha_{i t}^{N}\left(1+\frac{1}{\left(\varepsilon_{w}^{N}\right)_{i t}}\right),
$$

with $\left(\varepsilon_{w}^{N}\right)_{i t} \in \mathbb{R}_{+}$the wage elasticity of labor supply of firm $i$, measuring the degree of wage-setting power that firm $i$ possesses.

Using the first-order condition for intermediate inputs, we obtain an expression for firm $i$ 's pricecost markup $\left(\mu_{i t}\right)$ and using the first-order conditions with respect to intermediate inputs and labor, we define firm $i$ 's joint market imperfections parameter $\left(\psi_{i t}\right)$ as follows: 


$$
\begin{aligned}
& \mu_{i t}=\frac{\left(\varepsilon_{M}^{Q}\right)_{i t}}{\alpha_{i t}^{M}}, \\
& \psi_{i t}=\frac{\left(\varepsilon_{M}^{Q}\right)_{i t}}{\alpha_{i t}^{M}}-\frac{\left(\varepsilon_{N}^{Q}\right)_{i t}}{\alpha_{i t}^{N}} \\
& =0 \quad \text { if } L M S=P R, \\
& =\mu_{i t} \gamma_{i t}\left[\frac{1-\alpha_{i t}^{N}-\alpha_{i t}^{M}}{\alpha_{i t}^{N}}\right]>0 \quad \text { if } L M S=E B, \\
& =-\mu_{i t} \frac{1}{\left(\varepsilon_{w}^{N}\right)_{i t}}<0 \quad \text { if } L M S=M O .
\end{aligned}
$$

\section{Econometric model}

In order to obtain consistent estimates of the output elasticities $\left(\varepsilon_{N}^{Q}\right)_{i t}$ and $\left(\varepsilon_{M}^{Q}\right)_{i t}$, we only consider production functions with $(i)$ a scalar Hicks-neutral productivity term which is observed by the firm but unobserved by the econometrician (denoted by $\omega_{i t}$ ) and (ii) common technology parameters, governing the transformation of inputs to units of output, across a set of producers (denoted by the vector $\boldsymbol{\beta}$ ). These two assumptions imply the following expression for the production function:

$$
Q_{i t}=F\left(N_{i t}, M_{i t}, K_{i t} ; \boldsymbol{\beta}\right) \exp \left(\omega_{i t}\right) .
$$

In order to obtain consistent estimates of the production function coefficients $(\boldsymbol{\beta})$ for each of our 28 two-digit industries (which are defined in Section 5), we need to control for unobserved productivity shocks $\omega_{i t}$, which are potentially correlated with the firm's input choices. Following Dobbelaere and Kiyota (2018), we apply the estimation procedure proposed by Ackerberg et al. (2015) using the insight that optimal input choices hold information about unobserved productivity. We denote the logs of $Q_{i t}, N_{i t}, M_{i t}$ and $K_{i t}$ by $q_{i t}, n_{i t}, m_{i t}$ and $k_{i t}$, respectively.

We impose the following timing assumptions. Capital $k_{i t}$ is assumed to be decided a period ahead (at $t-1$ ) because of planning and installation lags. Labor is "less variable" than material. More precisely, $n_{i t}$ is chosen by firm $i$ at time $t-b(0<b<1)$, after $k_{i t}$ being chosen at $t-1$ but prior to $m_{i t}$ being chosen at $t$. This assumption is consistent with firms needing time to train new workers, with firms facing significant hiring or firing costs for labor, or with labor contracts being long term.

We assume that productivity $\left(\omega_{i t}\right)$ evolves according to an endogenous first-order Markov process. In particular, we allow a firm's decision to export (denoted $E X P_{i t-1}$ ) to endogenously affect future productivity, which is supported by evidence in international economics applications (the Melitz's selection effect; see e.g. Helpman (2006) and Bernard et al. $(2007,2012)$ for reviews of empirical evidence on the positive exporter productivity premium). As such, we can decompose $\omega_{i t}$ into its conditional expectation given the information known by the firm in $t-1$ (denoted $I_{i t-1}$ ) and a random innovation to productivity (denoted $\xi_{i t}$ ):

$$
\omega_{i t}=\mathbb{E}\left[\omega_{i t} \mid I_{i t-1}\right]+\xi_{i t}=\mathbb{E}\left[\omega_{i t} \mid \omega_{i t-1}, E X P_{i t-1}\right]+\xi_{i t}=g\left(\omega_{i t-1}, E X P_{i t-1}\right)+\xi_{i t},
$$


with $g(\cdot)$ a general function. $\xi_{i t}$ is assumed to be mean independent of the firm's information set at $t-1$.

Given these timing assumptions, firm $i$ 's intermediate input demand at $t$ depends directly on $n_{i t}$ chosen prior to $m_{i t}$, i.e. the input demand function for $m_{i t}$ is conditional on $n_{i t}$ :

$$
m_{i t}=m_{t}\left(n_{i t}, k_{i t}, E X P_{i t}, \omega_{i t}\right) .
$$

Eq. (16) shows that $\omega_{i t}$ is the only unobservable entering the intermediate input demand function. This scalar unobservable assumption together with the assumption that $m_{t}(\cdot)$ is strictly increasing in $\omega_{i t}$ conditional on $n_{i t}, k_{i t}$, and $E X P_{i t}$ (strict monotonicity assumption) ${ }^{6}$, allow to invert $\omega_{i t}$ as a function of observables:

$$
\omega_{i t}=m_{t}^{-1}\left(m_{i t}, n_{i t}, k_{i t}, E X P_{i t}\right)
$$

Considering the logarithmic version of Eq. (14) and allowing for an idiosyncratic error term including non-predictable output shocks and potential measurement error in output and inputs $\left(\epsilon_{i t}\right)$ gives:

$$
y_{i t}=f\left(n_{i t}, m_{i t}, k_{i t} ; \boldsymbol{\beta}\right)+\omega_{i t}+\epsilon_{i t},
$$

where $y_{i t}=q_{i t}+\epsilon_{i t}$ with $\epsilon_{i t}$ assumed to be mean independent of current and past input choices. ${ }^{7}$

We approximate $f(\cdot)$ by a second-order polynomial where all logged inputs, logged inputs squared and interaction terms between logged inputs are included (translog production function):

$$
\begin{aligned}
y_{i t}=\beta_{0} & +\beta_{n} n_{i t}+\beta_{m} m_{i t}+\beta_{k} k_{i t}+\beta_{n n} n_{i t}^{2}+\beta_{m m} m_{i t}^{2}+\beta_{k k} k_{i t}^{2} \\
& +\beta_{n m} n_{i t} m_{i t}+\beta_{n k} n_{i t} k_{i t}+\beta_{m k} m_{i t} k_{i t}+\omega_{i t}+\epsilon_{i t},
\end{aligned}
$$

where $\beta_{0}$ has to be interpreted as the mean efficiency level across firms.

Substituting Eq. (17) in Eq. (19) results in a first-stage equation of the form:

$$
y_{i t}=f_{i t}+m_{t}^{-1}\left(m_{i t}, n_{i t}, k_{i t}, E X P_{i t}\right)+\epsilon_{i t}=\varphi_{t}\left(n_{i t}, m_{i t}, k_{i t}, E X P_{i t}\right)+\epsilon_{i t},
$$

which has the purpose of separating $\omega_{i t}$ from $\epsilon_{i t}$, i.e. eliminating the portion of output $y_{i t}$ determined by unanticipated shocks at time $t$, measurement error or any other random noise $\left(\epsilon_{i t}\right)$.

Hence, the first stage involves using Eq. (20) and the moment condition $\mathbb{E}\left[\epsilon_{i t} \mid I_{i t}\right]=0$ to obtain an estimate $\widehat{\varphi}_{i t}$, of the composite term $\varphi_{t}\left(n_{i t}, m_{i t}, k_{i t}, E X P_{i t}\right)=f_{i t}+m_{t}^{-1}\left(m_{i t}, n_{i t}, k_{i t}, E X P_{i t}\right)$, which represents output net of $\epsilon_{i t}$. In our application, estimation of Eq. (20) is implemented by regressing output on a second-order polynomial series expansion where all logged inputs, logged inputs squared and interaction terms between logged inputs are included. To allow for time variation in $\varphi_{t}$, these polynomial terms are interacted with a time trend.

\footnotetext{
${ }^{6}$ Levinsohn and Melitz (2002) show that this strict monotonicity assumption holds as long as more productive firms do not set inordinately higher price-cost markups than less productive firms. Under Cournot competition, lower marginal costs (higher $\omega_{i t}$ ) lead to an increase in a firm's usage of intermediate inputs at any level of residual demand.

${ }^{7}$ Note that $\left(\varepsilon_{N}^{Q}\right)_{i t}=\frac{\partial \ln F(\cdot)}{\partial \ln N_{i t}}$ and $\left(\varepsilon_{M}^{Q}\right)_{i t}=\frac{\partial \ln F(\cdot)}{\partial \ln M_{i t}}$. These output elasticities are by definition independent of a firm's productivity shock.
} 
Given a particular set of parameters $\boldsymbol{\beta}$, we can compute (up to a scalar constant) an estimate of $\omega_{i t}$ :

$$
\begin{aligned}
\widehat{\omega}_{i t}(\boldsymbol{\beta})= & \widehat{m}_{t}^{-1}\left(m_{i t}, n_{i t}, k_{i t}, E X P_{i t}\right) \\
= & \widehat{\varphi}_{i t}-\beta_{0}-\beta_{n} n_{i t}-\beta_{m} m_{i t}-\beta_{k} k_{i t}-\beta_{n n} n_{i t}^{2}-\beta_{m m} m_{i t}^{2}-\beta_{k k} k_{i t}^{2} \\
& \quad-\beta_{n m} n_{i t} m_{i t}-\beta_{n k} n_{i t} k_{i t}-\beta_{m k} m_{i t} k_{i t} .
\end{aligned}
$$

In order to implement the second stage and to identify the production function coefficients, we need to recover the innovation to productivity $\left(\xi_{i t}\right)$ to form moments on. Using Eq. (21), a consistent (non-parametric) approximation to $\mathbb{E}\left[\omega_{i t} \mid \omega_{i t-1}, E X P_{i t-1}\right]$ is given by the predicted values from regressing nonparametrically $\widehat{\omega}_{i t}(\boldsymbol{\beta})$ on $\widehat{\omega}_{i t-1}(\boldsymbol{\beta})$ and $E X P_{i t-1}$. The residual from this regression provides us with an estimate of $\xi_{i t}$.

Given the timing assumptions on input use, the following population moment conditions can be defined: $\mathbb{E}\left[\xi_{i t}(\boldsymbol{\beta}) \boldsymbol{d}\right]=0$ where the set of instruments is:

$$
\boldsymbol{d}_{i t}=\left\{n_{i t-1}, m_{i t-1}, k_{i t}, n_{i t-1}^{2}, m_{i t-1}^{2}, k_{i t}^{2}, n_{i t-1} m_{i t-1}, n_{i t-1} k_{i t}, m_{i t-1} k_{i t}\right\} .
$$

Exploiting these moment conditions, we can now estimate the production function coefficients $\boldsymbol{\beta}$ using standard GMM and rely on block bootstrapping for the standard errors. The estimated production function coefficients $\widehat{\boldsymbol{\beta}}$ are then used together with data on inputs to compute the output elasticities at the firm-year level. In particular, we calculate the firm-year elasticity of output with respect to labor as:

$$
\left(\widehat{\varepsilon}_{N}^{Q}\right)_{i t}=\widehat{\beta}_{n}+2 \widehat{\beta}_{n n} n_{i t}+\widehat{\beta}_{n m} m_{i t}+\widehat{\beta}_{n k} k_{i t} .
$$

Similarly, we calculate the firm-year elasticity of output with respect to material as: ${ }^{8}$

$$
\left(\widehat{\varepsilon}_{M}^{Q}\right)_{i t}=\widehat{\beta}_{m}+2 \widehat{\beta}_{m m} m_{i t}+\widehat{\beta}_{m n} n_{i t}+\widehat{\beta}_{m k} k_{i t} .
$$

Using the shares of labor and intermediate input expenditure in total sales, $\alpha_{i t}^{N}$ and $\alpha_{i t}^{M}$, respectively, and our estimates of the output elasticities, $\left(\widehat{\varepsilon}_{N}^{Q}\right)_{i t}$ and $\left(\widehat{\varepsilon}_{M}^{Q}\right)_{i t}$, we are able to compute $\widehat{\mu}_{i t}$ and $\widehat{\psi}_{i t}$. Since we only observe $Y_{i t}=Q_{i t} \exp \left(\epsilon_{i t}\right)$, we do not observe the correct expenditure shares for $N_{i t}$ and $M_{i t}$. We can recover an estimate of $\epsilon_{i t}$ from the first stage to adjust the expenditure shares as follows: ${ }^{9}$

$$
\begin{aligned}
\widehat{\alpha}_{i t}^{N} & =\frac{w_{i t} N_{i t}}{P_{t} \frac{Y_{i t}}{\exp \left(\epsilon_{i t}\right)}}, \\
\widehat{\alpha}_{i t}^{M} & =\frac{j_{i t} M_{i t}}{P_{t} \frac{Y_{i t}}{\exp \left(\epsilon_{i t}\right)}} .
\end{aligned}
$$

Using Eqs. (23), (24), (25), and (26), we compute $\widehat{\mu}_{i t}$ and $\widehat{\psi}_{i t}$ as follows:

$$
\begin{aligned}
\widehat{\mu}_{i t} & =\frac{\left(\widehat{\varepsilon}_{M}^{Q}\right)_{i t}}{\widehat{\alpha}_{i t}^{M}}, \\
\widehat{\psi}_{i t} & =\frac{\left(\widehat{\varepsilon}_{M}^{Q}\right)_{i t}}{\widehat{\alpha}_{i t}^{M}}-\frac{\left(\widehat{\varepsilon}_{N}^{Q}\right)_{i t}}{\widehat{\alpha}_{i t}^{N}} .
\end{aligned}
$$

\footnotetext{
${ }^{8}$ Under a Cobb-Douglas production function $\left(\varepsilon_{N}^{Q}\right)_{i t}$ and $\left(\varepsilon_{M}^{Q}\right)_{i t}$ would be equal to $\widehat{\beta}_{n}$ and $\widehat{\beta}_{m}$, respectively.

${ }^{9}$ This correction is important as it eliminates any variation in expenditure shares that comes from variation in output not correlated with $\varphi_{t}(\cdot)$.
} 


\section{Classification and testing procedures}

\subsection{Classification procedure}

Estimates of $\widehat{\mu}_{i t}$ and $\widehat{\psi}_{i t}$ are used to define simultaneously the product market setting $P M S \in$ $\{P C, I C\}$ and labor market setting $L M S \in\{P R, E B, M O\}$ of firm $i$ at time $t$. Different combinations of product and labor market settings classify firm $i$ at time $t$ into a different regime of competitiveness $R \in \Re=\{P C-P R, I C-P R, P C-E B, I C-E B, P C-M O, I C-M O\}$. We apply the classification procedure of Dobbelaere and Mairesse (2013), which is summarized in Table 1.

$<$ Insert Table 1 about here>

\subsection{Testing procedure}

Distance test. Applying our classification procedure requires implementing a testing procedure that is capable of handling nonlinear restrictions on the parameters of the model and testing restrictions under the alternative as well as the null. We judge that the distance test of Kodde and Palm $(1984,1986)$ is best equipped to do so, given the flexibility in the type of restrictions on the parameters this test is able to cope with. To identify a firm's regime of competitiveness at any point in time, we implement the distance test through a system of MATLAB functions at the $10 \%$ significance level.

The distance test builds upon the earlier work of Nüesch $(1964,1966)$, Perlman (1969), and Gouriéroux et al. (1981, 1982). The latter propose the likelihood ratio, Kuhn-Tucker and Lagrange multiplier tests for nonlinear as well as linear models for hypothesis testing of the following form: $H_{0}: h(\boldsymbol{\theta})=\mathbf{0}$, against $H_{1}: h(\boldsymbol{\theta})>\mathbf{0}$. They show that the distribution of the different test statistics under the null is a weighted- $\chi^{2}$ distribution. The main empirical difficulty related to this large-sample hypothesis testing is the derivation of the weights of the weighted- $\chi^{2}$ distribution.

Let us introduce some notation in order to define the distance test in formal mathematical terms. Let $\boldsymbol{\theta}$ denote a $(p \times 1)$ vector of parameters of interest and let $h(\boldsymbol{\theta})$ be a continuous function denoting the restrictions on the parameters. Assume $\boldsymbol{\theta}$ can be consistently estimated by $\overline{\boldsymbol{\theta}}$. Let $\boldsymbol{\Omega}$ denote the variance-covariance matrix of $\boldsymbol{\theta}$, which can be consistently estimated by $\overline{\boldsymbol{\Omega}}$. Now, transform $\boldsymbol{\theta}$ and $\overline{\boldsymbol{\theta}}$ into new parameter vectors as follows (Kodde and Palm, 1984, 1986):

$$
\boldsymbol{\gamma}=N^{\frac{1}{2}} h(\boldsymbol{\theta}) \quad \text { and } \quad \bar{\gamma}=N^{\frac{1}{2}} h(\overline{\boldsymbol{\theta}}),
$$

where $N$ denotes the sample size.

The variance-covariance matrix of $\gamma$ and $\bar{\gamma}$ are

$$
\boldsymbol{\Sigma}=\frac{\partial h(\boldsymbol{\theta})}{\partial \boldsymbol{\theta}^{\prime}} \boldsymbol{\Omega} \frac{\partial h(\boldsymbol{\theta})^{\prime}}{\partial \boldsymbol{\theta}} \quad \text { and } \quad \overline{\boldsymbol{\Sigma}}=\frac{\partial h(\overline{\boldsymbol{\theta}})}{\partial \overline{\boldsymbol{\theta}}^{\prime}} \overline{\boldsymbol{\Omega}} \frac{\partial h(\overline{\boldsymbol{\theta}})^{\prime}}{\partial \overline{\boldsymbol{\theta}}} .
$$


Finally, define the distance function in the metric of $\boldsymbol{\Sigma}$ of a vector $\boldsymbol{\mu}$ from the origin, as:

$$
\|\boldsymbol{\mu}\|=\boldsymbol{\mu}^{\prime} \boldsymbol{\Sigma}^{-1} \boldsymbol{\mu}
$$

Kodde and Palm $(1984,1986)$ distinguish five different equality and inequality restrictions, which all slightly alter the definition of the test. To implement our classification procedure, we only need the following three definitions of the test: $(i)$ a standard test for zero under the null, $(i i)$ a test for inequality restrictions under the null, and $(i i i)$ a test for inequality and equality restrictions under the null.

First, if the following equality restrictions are tested $H_{0}: \boldsymbol{\gamma}=\mathbf{0}$ against $H_{1}: \boldsymbol{\gamma} \neq \mathbf{0}$, the distance test becomes:

$$
D=\|\bar{\gamma}\|
$$

which is equivalent to the Wald test.

Second, the test of inequality restrictions under the null, $H_{0}: \boldsymbol{\gamma} \geqslant \mathbf{0}$ against $H_{1}: \boldsymbol{\gamma} \ngtr \mathbf{0}$, leads to the following test statistic:

$$
D=\|\bar{\gamma}-\tilde{\gamma}\|
$$

where $\tilde{\gamma}$ is the solution of

$$
\min _{\gamma \geqslant 0}\|\bar{\gamma}-\gamma\|
$$

so the distance test equals the minimum of $(34)$.

Third, if one is interested in testing the following hypothesis $H_{0}: \gamma_{1}=\mathbf{0}, \boldsymbol{\gamma}_{2} \geqslant \mathbf{0}$ against $H_{1}: \gamma_{1} \neq \mathbf{0}, \gamma_{2} \ngtr \mathbf{0}$, the distance test takes the following form:

$$
\begin{aligned}
D=\|\bar{\gamma}-\tilde{\gamma}\|= & \left(\bar{\gamma}_{2}-\tilde{\gamma}_{2}-\boldsymbol{\Sigma}_{21} \boldsymbol{\Sigma}_{11}^{-1} \bar{\gamma}_{1}\right)^{\prime}\left(\boldsymbol{\Sigma}_{22}-\boldsymbol{\Sigma}_{21} \boldsymbol{\Sigma}_{11}^{-1} \boldsymbol{\Sigma}_{12}\right)^{-1}\left(\bar{\gamma}_{2}-\tilde{\boldsymbol{\gamma}}_{2}-\boldsymbol{\Sigma}_{21} \boldsymbol{\Sigma}_{11}^{-1} \bar{\gamma}_{1}\right) \\
& +\bar{\gamma}_{1}^{\prime} \boldsymbol{\Sigma}_{11}^{-1} \bar{\gamma}_{1},
\end{aligned}
$$

where $\tilde{\gamma}_{2}$ is the solution of the program:

$$
\min _{\gamma_{2} \geqslant 0}\left(\bar{\gamma}_{2}-\gamma_{2}-\Sigma_{21} \boldsymbol{\Sigma}_{11}^{-1} \bar{\gamma}_{1}\right)^{\prime}\left(\boldsymbol{\Sigma}_{22}-\boldsymbol{\Sigma}_{21} \boldsymbol{\Sigma}_{11}^{-1} \boldsymbol{\Sigma}_{12}\right)^{-1}\left(\bar{\gamma}_{2}-\gamma_{2}-\boldsymbol{\Sigma}_{21} \boldsymbol{\Sigma}_{11}^{-1} \bar{\gamma}_{1}\right)
$$

Eqs. (34) and (36) can be solved by standard quadratic programming techniques (see Beale (1955) and Wolfe (1959)).

Let us now discuss the distribution of the different forms of the distance test. As mentioned earlier, the distance test follows in general a weighted- $\chi^{2}$ distribution but these distributions slightly differ across hypotheses. The different hypotheses and their respective distributions are discussed in the same order as above.

First, $H_{0}: \quad \gamma=\mathbf{0}$ against $H_{1}: \quad \gamma \neq \mathbf{0}$ boils down to the well-known Wald test, which is $\chi^{2}(p)$ distributed, with $p$ degrees of freedom (the number of restrictions). 
Second, for the problem of testing $H_{0}: \gamma \geqslant \mathbf{0}$ against $H_{1}: \gamma \ngtr \mathbf{0}$, the distribution of $D$ under $H_{0}$ is given by

$$
\mathbb{P}(D \geqslant c \mid \boldsymbol{\Sigma})=\sum_{i=0}^{p} \mathbb{P}\left(\chi^{2}(p-i) \geqslant c\right) w(p, i, \boldsymbol{\Sigma}),
$$

where $w(p, i, \boldsymbol{\Sigma})$ denotes the probability that $i$ of the $p$ elements of $\tilde{\gamma}$ are strictly positive.

Third, for the problem of $H_{0}: \gamma_{1}=\mathbf{0}, \gamma_{2} \geqslant \mathbf{0}$ against $H_{1}: \gamma_{1} \neq \mathbf{0}, \gamma_{2} \neq \mathbf{0}$, the test statistic follows the distribution

$$
\mathbb{P}(D \geqslant c \mid \boldsymbol{\Sigma})=\sum_{i=0}^{p-q} \mathbb{P}\left(\chi^{2}(p-i) \geqslant c\right) w\left(p-q, i, \boldsymbol{\Sigma}_{22}-\boldsymbol{\Sigma}_{21} \boldsymbol{\Sigma}_{11}^{-1} \boldsymbol{\Sigma}_{12}\right),
$$

where $w\left(p-q, i, \boldsymbol{\Sigma}_{22}-\boldsymbol{\Sigma}_{21} \boldsymbol{\Sigma}_{11}^{-1} \boldsymbol{\Sigma}_{12}\right)$ denotes the probability that $i$ of the $p-q$ elements of $\tilde{\boldsymbol{\gamma}}_{2}$ are strictly positive, with $q$ the number of equality restrictions and the variance-covariance matrix set equal to the conditional variance-covariance matrix of $\bar{\gamma}_{2}$ given $\bar{\gamma}_{1}$.

Weights in the distribution of the distance test. The weights in the weighted- $\chi^{2}$ distribution are the probability content of obtaining a fixed number of positive elements in the solution of the quadratic programming problems. Since the quadratic programming problems differ across hypotheses, so do the weights $w$. The weights $w$ are a function of $(i) m$ the number of elements of $\boldsymbol{\xi}$, (ii) $k$ the number of strictly positive values of $\boldsymbol{\xi}$, and (iii) $\boldsymbol{\Delta}$ the variance-covariance matrix of $\boldsymbol{\xi}$, such that $w(m, k, \boldsymbol{\Delta})$. Here $\boldsymbol{\xi}$ denotes the solution to one of the quadratic programming problems (34) or (36), i.e. $\tilde{\gamma}$ or $\tilde{\gamma}_{2}$, depending on the hypothesis. The number of combinations of zero and strictly positive values of $\boldsymbol{\xi}$ is $2^{m}$, so scales exponentially in the number of components of $\boldsymbol{\xi}$.

Different methods to determine the weights are present in the literature of inequality constraint testing. These different methods consist of $(i)$ closed-form solutions, (ii) numerical approximation algorithms, (iii) Monte Carlo simulation techniques, (iv) upper and lower bound approximations, $(v)$ statistical properties, and ( $v i)$ binomial distribution approximation. Closed-form solutions are derived by Kudo (1963), Shapiro (1985), Wolak (1987), and Shapiro (1988). Since the determination of closed-form solutions of the weights can be complex for a large number of elements $m$, multiple approximation approaches are developed. Numerical approximation methods are given by Siskind (1976), Bohrer and Chow (1978), Robertson and Wright (1983), and Robertson et al. (1988). Monte Carlo simulation techniques are proposed by Gouriéroux et al. (1982), Wolak (1987), Silvapulle (1996), Dardanoni and Forcina (1998), and Silvapulle and Sen (2011). The upper and lower bound approximation of Kodde and Palm $(1984,1986)$ circumvents the problem of determining the weights by approximating the critical values directly. In addition to the upper and lower bound approximation, Kodde and Palm $(1984,1986)$ derive a method to determine the weights using their statistical properties. Gouriéroux et al. (1982) propose the binomial distribution approximation to be a simple and fast approximation technique.

The general method of Kodde and Palm $(1984,1986)$ for calculating the weights can be used for cases $m \geqslant 4$, but entails the disadvantage that it scales exponentially in the number of components of $\boldsymbol{\xi}$. Monte Carlo simulation techniques may provide a solution as they do not have the caveat 
of scaling exponentially in $m$ but such techniques do not produce exact weights. The binomial approximation of Gouriéroux et al. (1982) greatly reduces the numerical problems of obtaining the weights. Lower and upper bounds (Kodde and Palm, 1984, 1986) may not be sufficient for every real world application and are therefore not considered. In this paper, we focus on the exact calculation of the weights, as $m$ stays relatively small. ${ }^{10}$

\section{Data}

We use Chinese firm-level data from the Annual Survey of Industrial Firms (ASIF) conducted by the National Bureau of Statistics (NBS) for the period 1999-2006. This is the most comprehensive and representative firm-level dataset in China, and surveyed firms contribute to the majority of China's industrial value added. The survey includes all industrial firms that are either stateowned or are non-state firms with sales above 5 million RMB (Chinese currency). ${ }^{11}$ In addition, we use complementary information including industry concordances and detailed price deflators for all nominal variables that capture price evolutions common to all firms in a narrowly defined industry, provided by Brandt et al. (2012). We select all firms located in the three most important economic zones in China: the Bohai Bay Economic Rim region surrounding Beijing and Tianjin in the north, the Yangtze River Delta region comprising Shanghai in the east and the Pearl River Delta metropolitan region in the south.

Output $(Q)$ is defined as real gross output measured by nominal production divided by a 4 digit industry output price index. Labor $(L)$ refers to the average number of permanent workers. Material input is defined as intermediate consumption deflated by an intermediate consumption price index. The latter is calculated using the output deflators and information from the 2002 national input-output table. Reflecting the higher level of aggregation of the Chinese input-output table, intermediate input deflators are at the 3-digit level. The capital stock $(K)$ is measured by the real capital stock, computed from tangible assets and investment based on the perpetual inventory method and using the Brandt-Rawski deflator (Perkins and Rawski, 2008) to deflate annual investment. Employee compensation includes wages, employee supplementary benefits, unemployment insurance, retirement benefits, health insurance, and housing benefits. Reported compensation, however, appears to underestimate total payments to labor. The median labor share, defined as the share of value added which is payed out to workers, is only 28.1\%. By comparison, the national income accounts suggest a median share of labor around $50 \%$. Therefore, we follow Hsieh and Klenow (2009) and Brandt et al. (2012) by inflating the median wage share to half of the value added to approximate the fraction in the national accounts. The shares of labor $\left(\alpha^{N}\right)$ and material input $\left(\alpha^{M}\right)$ are constructed by dividing respectively the firm total labor cost and undeflated intermediate consumption by the firm undeflated production.

\footnotetext{
${ }^{10}$ A simulation study was performed to assess the performance of different approximation methods, namely ( $i$ ) a Monte Carlo simulation technique and (ii) a binomial approximation. The objective of such comparison is to identify robustness and reliability of the approximation methods. This serves the purpose of encouraging the empirical applicability of the distance test, as it has a wide usage in applied economic research. We find that both approximation methods provide adequate to very accurate approximations of the true weights, while being computationally less demanding compared to computing the exact weights (results not reported but available upon request).

${ }^{11}$ Approximately $\$$ US 600,000 over this period, a time when manufacturing prices were relatively stable.
} 
We focus only on manufacturing firms, assigning firms to 28 two-digit industries. We deleted observations with cost shares greater than or equal to one and smaller than or equal to zero. We also disregarded observations with top and bottom 1 percentiles in industry-year cost shares to remove outliers. We selected firms that survive at least four consecutive years because lagged inputs are needed to construct moment conditions in our estimation framework. Our estimation sample consists of 57,577 firms. Table A.1 in Appendix reports the panel structure of the estimation sample. Table A.2 reports the number of observations and firms by industry. Table 2 reports the means, standard deviations, and quartile values of the main variables in our estimation sample.

\section{$<$ Insert Table 2 about here $>$}

To identify the impact of trade liberalization on the extensive and intensive margins of product and labor market power, we exploit variation in tariff reductions across industries, following Lu and $\mathrm{Yu}$ (2015) and Brandt et al. (2017). In early 2002, China started to fulfill its tariff reduction responsibilities as a WTO member. According to the WTO accession agreement, China was required to complete tariff reductions by 2004. We exploit the fact that industries that have previously been more protected (i.e. with higher tariffs) experienced greater tariff reduction under WTO agreement and therefore higher degrees of liberalization whereas previously more open industries (i.e. with lower tariffs) witnessed small tariff reductions and therefore less liberalization. Presumably, China was required to reduce tariffs to WTO-determined levels, which are quite uniform across products, whereas pre-WTO tariff varied widely across products. As a consequence, both the average and dispersion of tariffs across industries fell.

Product-level tariff rates at the 8-digit level of the Harmonized System product classification are mapped into China's Industrial Classification (CIC) system at the 4-digit level to obtain output tariffs that we use in the firm-level analysis. Input tariffs are a weighted average of output tariffs, using as weights the industry shares from the off-diagonal elements of the 2002 input-output table. Given that the input-output table is defined at the 3-digit level, so are the input tariffs. Over the period 1998-2006, average output tariffs fell from close to $20 \%$ to nearly $9 \%$, whereas average input tariffs dropped from slightly over $15 \%$ to just above $7 \%$. Hence, we observe not only tariff compression within each tariff type, but also a narrowing gap between the two tariff types.

\section{Regimes of competitiveness}

The panel nature of the data enable us to investigate time variation in a firm's regime of competitiveness over the period 2000-2006. Given the large number of firms, we present results at the industry level which we obtain by aggregating the firm-year results. More specifically, the firm-year number of occurrences are aggregated at the industry level by summing up the firm-year level occurrences weighted by their share of value added for all firms within the industry, i.e.:

$$
\sum_{i \in \mathfrak{I}} w_{i}(\# \text { of occurrences of regime } R \text { ), }
$$

where $\mathfrak{I}$ denotes the set of firms contained in industry $j$ and $w_{i}$ denotes the weight defined as the share of value added of firm $i$. The weighted frequencies of occurrence of competitiveness regimes 
are obtained by dividing the aggregated weighted number of occurrences by the weighted number of observations within the industry, i.e.:

$$
\frac{\sum_{i \in \mathfrak{I}} w_{i}(\# \text { of occurrences of regime } R)}{\sum_{i \in \mathfrak{I}} w_{i}} .
$$

The prevailing regime at the industry level is the regime that has the highest frequency of occurrence. Since this prevailing industry-specific regime masks time variation in dominant regimes for a particular industry, we first look at the evolution of industry-specific dominant regimes over time. This is accomplished by aggregating firm-year number of occurrences at the industry-year level using the same weighted sum as discussed above. The dominant industry-year regime is the regime with the highest weighted frequency of occurrence. When the maximum weighted frequency occurs at multiple regimes, the first regime encountered is chosen to be the dominant regime. Table 3 presents variation in regimes of competitiveness over the period 2000-2006 at the industry level.

\section{$<$ Insert Table 3 about here>}

Table 3 shows that $25 \%$ of industries ( 7 out of 28 ) observe at least one change in competitiveness regime over time. This apparent stability suggests that the impact of WTO membership is relatively modest. Besides, some of the switches in regimes over time that do occur are caused by the inconclusiveness of the distance test, i.e. for some firms and years the distance test is not able to identify a single regime of competitiveness (see Section 7.2).

Let us now turn to the regimes of competitiveness that prevail in each of the 28 industries, which we present in Table 4. The frequencies are denoted as fractions and are ranked according to an industry's dominant regime and within the dominant regime on the basis of the highest weighted frequency of occurrence. These frequencies may not necessarily sum up to $100 \%$ due to the inconclusiveness of the distance test.

\section{$<$ Insert Table 4 about here $>$}

Table 4 reveals that perfect competition in both product and labor markets is not very common across Chinese manufacturing industries, with an average fraction of occurrence well below $10 \%$. This confirms expectations as the $P C$ - $P R$ regime of competitiveness is often thought to be a philosophical benchmark. The two most dominant regimes of competitiveness at the industry level are $I C-E B$ and $I C-M O$, with an average fraction of occurrence above $90 \%$ for the former and about $28 \%$ for the latter. These dominant regimes indicate that most industries operate under imperfect competition in product and labor markets, they seem to differ mainly in their labor market setting. The large fraction of occurrence of the $I C$ - $E B$ regime is compatible with recent evidence on the role of workers' bargaining power in shaping the wage distribution in China over the period 2000-2007, which could be based on risk sharing between firms and workers (Duan and Martins, 2018) or fair wage (Kamal et al., 2015) arguments. Given that many formal labor market institutions (such as collective bargaining, independent trade unions, forms of social protection) are still at a relatively early stage of development, our findings are far less likely explained by effective union bargaining power. Indeed, trade unions are indirectly controlled by the government and China's communist party through their affiliation with the single national organization (the All-China Federation of 
Trade Union, ACFTU). There is, however, evidence on the collective voice role of Chinese unions, including mediating labor disputes, monitoring implementation of the Labor Law and promoting employee training, which is also compatible with our results (Ge, 2007; Lu et al., 2010; Budd et al., 2014).

Let us now discuss the volatility of competitiveness regimes at the industry level. Regime changes at the firm level are determined by comparing the regime of the first year available for firm $i$ with that of the final year available, i.e. $R_{i T}-R_{i 0}$, where $T$ and 0 denote respectively the final and first year available for firm $i$. The firm-level average changes in regime are aggregated at the industry level. The variation of the average change in regime of competitiveness at the industry level is visualized in Figure 1, where industries are ranked by the number of firms within each industry. Each circle represents an industry, where the center of the circle denotes the average change and the radius corresponds to a measure of variation (standard deviation) of the average change. Table A.3 in Appendix presents the average change in regime of competitiveness at the industry level and within-industry variation underlying Figure 1.

\section{$<$ Insert Figure 1 about here $>$}

From Figure 1, it is clear that the size of the industry does not have an effect on the average number of regime changes at the industry level. The average change lies just below one, with not much variation across industries. However, there is more variability in the standard deviation of the average change: some industries display a standard deviation just short of two, while some others have little to no variation. This within-industry variation could be explained by differential effects of WTO entry on different subgroups within industries, which we examine in the next sections.

\section{Impact of WTO accession on the extensive margin of product and labor market power}

\subsection{Descriptive analysis of WTO entry effect}

Let us now turn to discussing the documented changes in regimes in light of China's accession to the WTO at the end of 2001. WTO membership might have exerted positive effects on the Chinese domestic economy. There are various channels through which trade policy changes might impact competition among sellers in goods markets. Input tariff liberalization reduces a firm's marginal costs through lowering input prices or increasing technical (within-firm) efficiency via an increase in the access to imported intermediate inputs of higher quality and broader variety. Output tariff liberalization directly exposes firms to intensified import competition through changing the residual demand they face, either through shifting residual demand curves of survivors down, or through increasing the demand elasticity that domestic firms perceive. This direct procompetitive effect causes firms to adjust by lowering price-cost markups. Output tariff liberalization might also exert an indirect effect through hiring better managers, changing the organization structure, thereby reducing X-inefficiencies and increasing within-firm productivity. Which effect dominates, is a priori not clear. Firm $i$ 's price-cost markup $\left(\mu_{i t}\right)$ is a principal input in the characterization of its regime of competitiveness: it determines its product market setting and is a component of its joint 
market imperfections parameter $\left(\psi_{i t}\right)$, which determines its labor market setting. For example, a downward pressure on price-cost markups would induce a shift towards the $P C$-product market setting.

The impact of WTO membership on a firm's labor market setting is a priori not clear, either. Highproductive (and thus high-profit firms) might be more willing to share rents with their workers according to a surplus-sharing rule, yielding an increase in the frequency of $E B$-labor market setting occurrences. On the other hand, high-productive (low marginal-cost firms) firms might expand their market share. Larger firms might be less likely to negotiate and more willing to use wage posting because they can better process the larger pool of applicants created if recruitment technology is better in large firms. This might increase the frequency of $M O$-labor market setting occurrences.

To study these effects, Table 5 reports the difference-in-difference in weighted frequency of occurrence of each regime compared to the dominant regime of competitiveness at the industry level before WTO entry (years 2000-2001) and after WTO entry (years 2002-2006), i.e.:

$$
\Delta\left(\frac{\sum_{i \in \mathfrak{I}} w_{i}[(\# \text { of occurrences of regime } R)-(\# \text { of occurrences of regime } \hat{R})]}{\sum_{i \in \mathfrak{I}} w_{i}}\right),
$$

where $\hat{R}$ denotes the dominant regime. $\Delta$ denotes the difference operator, defined as the difference between the pre-WTO period and the post-WTO period.

\section{$<$ Insert Table 5 about here>}

Such differences-in-differences approach allows us to provide suggestive evidence on the impact of WTO accession on shifts in industries' dominant regimes of competitiveness. A large absolute value of the difference-in-difference change of certain regimes would suggest an impact of WTO membership on the regime of competitiveness in which firms/industries operate. ${ }^{12}$ In order to highlight the importance of observed changes, we mark regimes in Table 5 as follows. First, * marks a regime displaying a difference-in-difference change exceeding 25 percentage points in absolute value. Second, ${ }^{\dagger}$ marks a regime that is more than 10 percentage points apart from the dominant regime prior to WTO entry and less than 10 percentage points apart after WTO entry. Third, $\ddagger$ marks a regime that is less than 10 percentage points apart from the dominant regime prior to WTO entry and is more than 10 percentage points apart after WTO entry.

Table 5 reveals little heterogeneity in WTO entry effects across regimes. Only a handful of changes are observed which may have influenced the identification of the dominant regime after WTO accession. ${ }^{13}$ Focusing on the product market setting, we find that the most relevant changes are in favor of the imperfectly competitive setting $(I C)$. $I C$ appears to be the dominant product market setting in both the pre-WTO and post-WTO periods. This suggests that the most likely

\footnotetext{
${ }^{12}$ This difference-in-difference change entails a composition effect as well as an WTO entry effect. The composition effect consists of changes in firms belonging to a specific regime during the period 2000-2006. The WTO entry effect refers to time variation in regimes due to e.g. trade liberalization. Isolating the causal impact of WTO accession on regimes of competitiveness requires disentangling both effects, which we indirectly do in Section 7.3.

${ }^{13}$ Changes that are marked with ${ }^{\dagger}$ or $\ddagger$.
} 
beneficiaries of trade liberalization in the short run are the domestic firms who benefit from lower production costs while simultaneously raising price-cost markups. Focusing on the labor market setting, we observe mostly a strengthening of the pre-WTO dominant regime. As such, we mainly find a consolidation of pre-WTO dominant regimes after WTO accession. Hence, we do not find suggestive evidence for a decline in (factor) price distortions after trade liberalization, i.e. we do not observe a trend towards a perfectly competitive product/labor market setting $(P C / P R)$. Recall that these are markets settings in which firms firms set prices equal to marginal costs/pay real wages equal to the marginal product of labor (that is, in which firms do not exert product/labor market power).

\subsection{Inconclusiveness of the distance test}

The distance test is inconclusive in identifying a firm's regime of competitiveness at any point in time in $44 \%$ of the cases. In $72 \%$ of these inconclusive cases, the test is in doubt between two regimes. This inconclusiveness may be attributed to the fact that, in reality, firms seldom operate under a single theoretical extreme of both the product and labor market setting spectrum. Instead, it is more realistic to assume that firms operate under a hybrid combination of several extreme product and labor market settings. Such hybrid combination of labor market settings that may be prevalent in reality is that of efficient bargaining and monopsony as firms engage in some sort of risk-sharing (favoring $E B$ ) and have some local monopsony power due to job characteristics or lack of labor mobility (favoring $M O$ ). Another interpretation of the inconclusiveness of the distance test is that firms might be in a transition phase between different regimes due to trade liberalization following WTO entry. However, the fraction of inconclusive cases in the pre-WTO period is not significantly different from the one in the post-WTO period, which does not seem to support the latter interpretation. ${ }^{14}$

Let us now explore the nature of this inconclusiveness. We start by investigating the composition of the inconclusiveness. We observe that a large fraction of inconclusive cases arises due to inconclusiveness between two regimes. Figure 2 shows that there is large heterogeneity across industries in terms of both the level and composition of inconclusiveness. The inconclusive cases are composed of inconclusiveness between more than two regimes and inconclusiveness between two regimes, which we label as severe and mild inconclusiveness, respectively. This large heterogeneity across industries indicates that there might be some underlying factor/economic variable that is driving such differences.

\section{$<$ Insert Figure 2 about here $>$}

Figure 3 shows that industry size is an important determinant of inconclusiveness at the industry level. More specifically, there appears to be a strong negative relationship between inconclusiveness and industry size. In order to investigate the determinants of the inconclusiveness in more detail, we estimated a probit model including several firm characteristics, such as capital intensity, size,

\footnotetext{
${ }^{14}$ The difference in fraction of inconclusive cases is in the order of 0.3 percentage points between the two periods. For the fraction of inconclusive cases where the distance test is in doubt between two regimes of competitiveness, this difference is in the order of 0.2 percentage points.
} 
export status, region, and ownership type. Besides these firm characteristics, we also included industry fixed effects and a pre-WTO period indicator. Only the region and ownership type play a minor role in explaining the observed inconclusiveness. Figure 3 also reveals that there is a "gap" for small industries compared to medium-large industries between total inconclusiveness and inconclusiveness between two regimes. For medium and large industries, the inconclusiveness between two regimes accounts for $80-90 \%$ of the total inconclusiveness, while for small industries this fraction is around $50-60 \%$.

\section{$<$ Insert Figure 3 about here $>$}

In order to understand this difference between the small and medium-large industries, we look at the conditional inconclusiveness of the product and labor market settings. Figure 4 shows the inconclusiveness due to inconclusiveness related to the product (labor) market setting conditional on being able to identify the labor (product) market setting. We observe that, conditional on being able to identify the product market setting, we are able to identify the labor market setting as well in almost all cases, i.e. conditional on conclusiveness on the product market setting there is almost no inconclusiveness on the labor market setting. However, Figure 4 shows that this does not hold for conditional inconclusiveness of the product market setting. Conditional on being able to identify the labor market setting, the inconclusiveness on the product market setting is $50-70 \%$ for small industries and goes down to around $20 \%$ for large industries. As such, we observe that almost all inconclusiveness between two regimes is driven by conditional $P M S$-inconclusiveness. This result supports our conjecture that inconclusiveness is driven by the fact that firms seldom operate under a theoretical extreme of both the product and labor market setting spectrum, as we only consider two possible product market settings, while we consider three possible labor market settings.

\section{$<$ Insert Figure 4 about here $>$}

Our probit results on the conditional $P M S$-inconclusiveness confirm the previous findings. As such, we conclude that firm characteristics neither significantly nor economically explain the observed difference in inconclusiveness between small and medium-large industries. Therefore, we focus on a different (possible) explanation, namely the fact that the translog production function estimates are performed at the 2-digit industry level. This implies that the precision of these production functions estimates is higher for large industries. The distance test uses the output elasticities through the price-cost markup $(\mu)$ and joint market imperfection parameter $(\psi)$ as inputs, hence, it relies on the precision of the elasticities. Therefore, the difference in precision of the output elasticities for large and small industries could possibly explain the difference in inconclusiveness. In order to determine whether this difference in precision is significant, we perform a variancedecomposition on the difference in variance of the output elasticities for large and small industries. In this decomposition, we consider the difference in the average variance for a large and a small industry. The decomposition decomposes the difference in variance into two parts. The first part corresponds to the difference in precision of the production function estimates, keeping the input factors constant at the large industry average. The second part corresponds to the difference in input factors, keeping the precision of the production function estimates at the level of the small 
industry. This decomposition can then be interpreted as separating the difference in variances into a part related to the difference in precision due to different sample sizes and a part related to the difference in input factors. This variance-decomposition is done pair-wise for each smalllarge industry combination. The results of this decomposition indicate that differences in the precision of the production function estimates explain the downward sloping gradient for industry size observed in Figures 3 and 4. In general, these differences in precision account for more than $80 \%$ of differences in precision between a large and small industry for the output elasticities with respect to both labor and intermediate inputs. These findings are robust to classifying small industries as falling below the 25th-, 50th-, or 75th-percentile of the industry size distribution.

7.3. Impact of WTO entry on switching away from exerting product/labor market power

In order to establish causal evidence of trade liberalization on firms' market power, we deal with the inconclusiveness of the distance test by applying an allocation rule. More specifically, we first select all conclusive cases and the subset of inconclusive cases in which the distance test is inconclusive between either two or three regimes (which amounts to $80 \%$ of the inconclusive cases) ${ }^{15}$. Second, if - conditional on this selection - a firm has a dominant product/labor market setting in the pre-WTO period, we assign a dominant product/labor market setting to that inconclusive (hence, missing) product/labor market setting. We define a firm's dominant product/labor market setting in the pre-WTO period based on the highest frequency of occurrence. Our core set of results are robust to not applying such allocation rule. ${ }^{16}$

In our extensive margin analysis, we divide firms into stayers and switchers for a specific product/labor market setting. This stayer-switcher analysis allows us to identify the effect of trade liberalization conditional on the pre-WTO product/labor market setting. Such analysis identifies the impact of trade liberalization on the likelihood of switching away from the pre-WTO product/labor market setting in the post-WTO period relative to staying in the pre-WTO product/labor market setting.

Firms belong to the category of stayers if their pre- and post-WTO product/labor market setting is the same. Firms are categorized as switchers if their pre-WTO product/labor market setting is different from their post-WTO product/labor market setting, where switching behavior is relative to the pre-WTO product/labor market setting. For example, an $E B$-switcher is a firm that switches from an $E B$-labor market setting in the pre-WTO period to either a $P R$ - or $M O$-labor market setting in the post WTO period. ${ }^{17}$.

If the distance test produces inconclusive results in the pre- or post-WTO period, we assign the product/labor market setting for which we have most evidence. This boils down to applying our earlier described allocation rule to the pre- and post-WTO period separately. This implies that observations are excluded from the stayer-switcher analysis in two cases. The first case is when the

\footnotetext{
${ }^{15}$ The composition of inconclusiveness for this subset is shown in Figure A.1. The inconclusiveness and conditional inconclusiveness as a function of industry size are depicted in Figures A.2 and A.3, respectively.

${ }^{16}$ Results not reported but available upon request.

${ }^{17}$ Remark that switching from $E B$ to $M O$ is a hypothetical example as such switches are rare. The same holds for $M O$-to- $E B$ switches.
} 
test produces conclusive results which indicate different product or labor market settings within the pre- and/or post-WTO periods. The second case is when the test produces inconclusive results which do not provide enough information/evidence in favor of a specific product and/or labor market setting.

We postulate that firm $i$ 's product market setting at time $t$ might depend on the degree of trade liberalization, other observable characteristics as well as unobservable factors $\epsilon$ such as managerial ability. Suppressing firm and time subscripts ( $i$ and $t$, respectively) for simplicity, we thus have:

$$
P M S^{*}=\beta_{0}+\beta_{1} \text { input tariff }+\beta_{2} \text { output tariff }+\boldsymbol{z}^{\prime} \beta_{z}+\epsilon,
$$

where input tariff and output tariff denote the 1-year lagged values of the policy variables input tariffs and output tariffs, respectively. To control for two ongoing policy reforms in the early 2000s (SOEs reform and relaxation of FDI regulations), the vector $\boldsymbol{z}$ comprises industry-year varying variables such as the share of state-owned sales and the share of foreign-owned sales in total sales. It also includes a firm's size (number of workers) and a full set of year fixed effects in order to control for macroeconomic shocks common to all firms.

In order to investigate the link between the degree of trade liberalization and the likelihood of switching away from imperfect competition in the product market (that is, exerting product market power), we specify the following probit model:

$$
\mathbb{P}(I C \text {-switch } \mid \boldsymbol{x})=\Phi\left(\boldsymbol{x}^{\prime} \beta\right) .
$$

The vector $\boldsymbol{x}$ includes the regressors specified in Eq. (39).

Whether market power in firm $i$ in period $t$ is consolidated on either the supply side or the demand side of labor might be influenced by common observable as well as unobservable factors such as a firm's corporate culture. In order to investigate the link between the degree of trade liberalization and the likelihood of switching away from either efficient bargaining (that is, paying a wage markup) or monopsony (that is, setting a wage markdown), we specify the following univariate probit models:

$$
\begin{array}{ll}
L M S_{m}^{*}=\boldsymbol{x}_{m}^{\prime} \beta_{m}+\epsilon_{m}, & m=1,2 \\
L M S_{m}=I\left(L M S_{m}^{*}>0\right), & m=1,2
\end{array}
$$

where $L M S_{1}=\mathbb{P}(E B$-switch $\mid \boldsymbol{x})$ and $L M S_{2}=\mathbb{P}(M O$-switch $\mid \boldsymbol{x})$. We include the same regressors as in the univariate probit model defined in Eq. (40).

The results of this extensive margin stayer-switcher analysis are reported in Table 6. Columns 1, 4 and 7 present the marginal effect of our main regressors on the probability of switching away from the pre-WTO period product/labor market setting relative to staying in the pre-WTO period product/labor market setting in the univariate probit models. More specifically, column 1 reports how much the (conditional) probability of switching away from $P M S=I C$ in the postWTO period relative to staying changes when the value of a regressor changes, holding all other regressors constant whereas column 4 (7) shows how much the likelihood of switching away from $L M S=E B(L M S=M O)$ in the post-WTO period relative to staying changes. Accounting for heteroskedasticity and arbitrary autocorrelation, we cluster standard errors at the 4-digit industryyear level (level of treatment) for statistical inference and use within-industry and between-industry output share weights in all regressions. 
The marginal effects indicate that trade liberalization via either type of tariffs does not influence the likelihood of switching away from the imperfectly competitive product market setting relative to staying, which could be explained by the fact that only a small fraction of firms switches towards perfect competition in the product market. Moreover, only a small fraction of firms at any point in time is characterized by perfect competition in the product market.

However, trade policy changes via tariff reductions affect the likelihood that firms shift away from an imperfectly competitive labor market setting relative to staying, with the impact depending on both the mechanism that ties firm wages to firm performance and the type of tariffs. More specifically, input tariff cuts, which might increase technical efficiency through access to lowercost and superior intermediate products, decrease the likelihood of switching away from either paying wage markups, i.e. sharing rents based on the bargaining power of workers, or setting wage markdowns, i.e. sharing rents based on the firm's wage-setting power. The responsiveness of both labor market settings differs: a 1-percentage-point reduction in tariffs on intermediate inputs decreases the conditional probability of $E B$-switch and $M O$-switch by 3 and 20 percentage points, respectively. Contrary to this intermediate input channel of trade, we find that falling output tariffs, which decrease output prices and might decrease X-inefficiencies through reducing managerial slack and changing organizational structure, increase the likelihood that firms shift away from setting wages lower than the marginal revenue product of labor. In particular, a 1percentage-point reduction in output tariffs increases the conditional probability of $M O$-switch by 9 percentage points.

To check robustness, we also estimate the average effect of tariff reductions (and other dependent variables) on switching away from an imperfectly competitive product/labor market setting in a "representative enterprise" (see columns 2, 5 and 8 of Table 6). We also present TSLS estimates in which we use tariff rates from the WTO agreement (predetermined maximum tariff rates) as instruments for actual tariff rates in the post-WTO period to rule out a policy endogeneity concern associated with using nominal tariffs as reflecting the degree of government intervention. Estimating these linear probability models leads to similar conclusions as estimating the probit models discussed above.

\section{Impact of WTO accession on the intensive margin of product and labor market power}

In the previous section, we have provided causal evidence of a link between trade liberalization and the type (that is, the existence) of imperfections in the labor market at the firm level. From a policy perspective, it is equally important to understand whether trade liberalization in intermediateinput and final-goods industries has affected the degree of product and labor market imperfections. To establish such causal evidence, we estimate the average impact of input and output tariff reductions (and other independent variables) on the degree of product and labor market power, conditional on the relevant product/labor market setting. As such, we define the following regres- 
sion models:

$$
\begin{aligned}
\ln \widehat{\mu}_{i t} & =\alpha_{0}+\alpha_{1} \text { input tariff }_{j t-1}+\alpha_{2} \text { output tariff }_{j t-1}+\alpha_{3} I M R_{i t}+\alpha_{i}+\boldsymbol{z}^{\prime} \alpha_{z}+\zeta_{i t}, \\
\ln \left(\frac{\widehat{\phi}_{i t}}{1-\widehat{\phi}_{i t}}\right) & =\alpha_{0}+\alpha_{1} \text { input tariff }_{j t-1}+\alpha_{2} \text { output tariff }_{j t-1}+\alpha_{3} I M R_{i t}+\alpha_{i}+\boldsymbol{z}^{\prime} \alpha_{z}+\zeta_{i t}, \\
\ln \left(\widehat{\varepsilon}_{W}^{N}\right)_{i t} & =\alpha_{0}+\alpha_{1} \text { input tariff }{ }_{j t-1}+\alpha_{2} \text { output tariff }_{j t-1}+\alpha_{3} I M R_{i t}+\alpha_{i}+\boldsymbol{z}^{\prime} \alpha_{z}+\zeta_{i t},
\end{aligned}
$$

with $I M R$ the inverse Mills ratio from the respective probit model which we include to account for selection bias, $\alpha_{i}$ firm fixed effects, and the vector $z$ comprising the same regressors as in the extensive margin analysis. As before, we instrument applied tariffs in the post-WTO period with predetermined maximum tariff rates. As the share of rents captured by the workers $(\phi)$ lies within the $[0,1]$-range, we use a logit transformation to model the degree of workers' bargaining power during worker-firm negotiations.

\section{$<$ Insert Table 7 about here>}

Table 7 presents the average effect of the regressors in the three regression models. Our intensive margin results provide evidence of trade liberalization in intermediate-inputs industries having affected the degree of firms' product versus labor market power differently. Conditional on being characterized by $P M S=I C$, we find that a reduction in input tariffs increases the degree of product market power (price-cost markups), as expected and in line with Brandt et al. (2017) who find that cuts in input tariffs raise both price-cost markups and productivity. More specifically, each percentage point decline in tariffs on intermediate inputs increases the price-cost markup by 0.8 percent. Conditional on $L M S=M O$, each percentage point decline in input tariffs is found to decrease the firm's wage-setting power by 7.5 percent.

Similar to Section 7.3, we implement a stayer-switcher analysis to allow for different dynamics of product and labor market settings when investigating the impact of trade liberalization on the degree of product and labor market power. Instead of conditioning on the relevant product/labor market setting, we condition on being a stayer or a switcher for the relevant product/labor market setting. In this analysis, switchers are defined as switching towards a specific product/labor market setting. Such stayer-switcher analysis enables us to filter out the composition effect from the effect of trade policy changes on market power. By conditioning on being a stayer or a switcher, we include the same firms in both the pre- and post-WTO periods, while in the earlier analysis - in which we condition only on the product/labor market setting - we could potentially identify a combined effect (of true trade liberalization and composition).

\section{$<$ Insert Table 8 about here>}

From Table 8, it follows that, in general, the sign and magnitude of the input and output tariff effects are similar to the ones reported in Table 7 . This indicates that composition effects are not driving our results in the intensive margin analysis discussed above. 


\section{Conclusion}

How does firms' pricing behavior in product and labor markets respond to domestic trade liberalization? In spite of its importance for understanding the distributional consequences of trade shocks and the underlying sources of increased inter-firm wage disparities, this question has not been answered so far. This paper examines the impact of trade liberalization in intermediateinputs and final-goods industries on the extensive and intensive margins of product and labor market power of Chinese manufacturing firms.

We apply the methodology developed in Dobbelaere and Kiyota (2018) to estimate gaps between the marginal products of labor and intermediate inputs and their respective marginal costs which are used to recover our model consistent measures of product and labor market power. Intuitively, whether or not a firm sets a price above its marginal cost (price-cost markup) defines its product market power. Similarly, whether or not a firm pays a real wage above/below the marginal product of labor (wage markup/markdown) defines its labor market power. To identify a firm's regime of competitiveness, characterizing the product and labor market power that a firm possesses, at any point in time, we implement a procedure to test inequality restrictions, the distance test of Kodde and Palm (1986). To establish causal evidence of domestic trade liberalization on product and labor market power, we use China's accession to the World Trade Organization (WTO) in 2001 as an identification strategy.

We find that the intermediate input channel and the procompetitive channel work in opposite directions on the extensive margin of labor market power. Reducing tariffs on intermediate inputs decreases the likelihood of shifting firms away from either paying wage markups or setting wage markdowns whereas reducing tariffs on final goods increases the likelihood that firms move away from setting wage markdowns. Our intensive margin results highlight the importance of jointly analyzing the effect of trade policy changes on the degree of product and labor market power. Trade liberalization via input tariff reductions increases a firm's price-cost markup (conditional on exerting product market power) but decreases a firm's wage-setting power (conditional on setting wage markdowns).

Data limitations precluded us from disentangling the exact mechanisms by which firms adjust their pricing behavior in product and labor markets to changes in market environments induced by trade shocks. We leave such analysis for future research. 


\section{References}

Ackerberg, D. A., K. Caves and G. Frazer (2015): "Identification Properties of Recent Production Function Estimators". In: Econometrica 83.6, pp. 2411-2451.

Beale, E. M. L. (1955): "On Minimizing A Convex Function Subject to Linear Inequalities". In: Journal of the Royal Statistical Society. Series B (Methodological) 17.2, pp. 173-184.

Berger, D. W., K. F. Herkenhoff and S. Mongey (2019): "Labor Market Power". Working Paper 25719. National Bureau of Economic Research.

Bernard, A. B., J. B. Jensen, S. J. Redding and P. K. Schott (2007): "Firms in International Trade". In: Journal of Economic Perspectives 21.3, pp. 105-130.

- (2012): "The Empirics of Firm Heterogeneity and International Trade". In: Annual Review of Economics 4.1, pp. 283-313.

Bohrer, R. AND W. Chow (1978): "Algorithm AS 122: Weights for One-Sided Multivariate Inference". In: Journal of the Royal Statistical Society. Series C (Applied Statistics) 27.1, pp. 100104.

Brandt, L., T. Tombe And X. Zhu (2013): "Factor market distortions across time, space and sectors in China". In: Review of Economic Dynamics 16.1. Special issue: Misallocation and Productivity, pp. 39-58.

Brandt, L., J. Van Biesebroeck, L. Wang and Y. Zhang (2017): "WTO accession and performance of Chinese manufacturing firms". In: American Economic Review 107.9, pp. 27842820.

Brandt, L., J. Van Biesebroeck and Y. Zhang (2012): "Creative accounting or creative destruction? Firm-level productivity growth in Chinese manufacturing". In: Journal of Development Economics 97.2, pp. 339-351.

Brandt, L. And X. Zhu (2010): "Accounting for China's growth". mimeo.

Brooks, W. J., J. P. Kaboski, Y. A. Li And W. Qian (2019): "Exploitation of Labor? Classical Monopsony Power and Labor's Share". Working Paper 25660. National Bureau of Economic Research, pp. 1-44.

Budd, J. W., W. Chi, Y. Wang And Q. XIe (2014): "What Do Unions in China Do? ProvincialLevel Evidence on Wages, Employment, Productivity, and Economic Output". In: Journal of Labor Research 35.2, pp. 185-204.

Cai, F., A. Park and Y. Zhao (2008): "The Chinese Labor Market in the Reform Era". In: China's Great Economic Transformation. Ed. by L. Brandt And T. G. Rawski. Cambridge University Press, pp. 167-214.

Coşar, A. K., N. Guner And J. Tybout (2016): "Firm dynamics, job turnover, and wage distributions in an open economy". In: The American Economic Review 106.3, pp. 625-663.

Dardanoni, V. And A. Forcina (1998): "A Unified Approach to Likelihood Inference on Stochastic Orderings in a Nonparametric Context". In: Journal of the American Statistical Association 93.443, pp. 1112-1123. 
Davidson, C., S. J. Matusz And A. Shevchenko (2008): "Globalization and firm level adjustment with imperfect labor markets". In: Journal of International Economics 75.2, pp. 295309.

De Loecker, J. And P. K. Goldberg (2014): "Firm performance in a global market". In: Annual Review of Economics 6.1, pp. 201-227.

De Loecker, J. And J. Van Biesebroeck (2016): "Effect of international competition on firm productivity and market power". Tech. rep. National Bureau of Economic Research.

Di Giovanni, J., A. A. Levchenko And J. Zhang (2014): "The global welfare impact of China: trade integration and technological change". In: American Economic Journal: Macroeconomics 6.3, pp. $153-183$.

DobBelaere, S. AND K. KiYOTA (2018): "Labor market imperfections, markups and productivity in multinationals and exporters". In: Labour Economics 53, pp. 198-212.

Dobbelaere, S. And J. Mairesse (2013): "Panel data estimates of the production function and product and labor market imperfections". In: Journal of Applied Econometrics 28.1, pp. 1-46.

Duan, W. And P. Martins (2018): "Rent sharing in China: Magnitude, heterogeneity and drivers". Tech. rep. Centre of Globalisation Research, Queen Mary University of London.

Fajgelbaum, P. D. (2013): "Labor market frictions, firm growth, and international trade". Tech. rep. National Bureau of Economic Research.

Fan, S., X. Zhang And S. Robinson (2003): "Structural change and economic growth in China". In: Review of Development Economics 7.3, pp. 360-377.

Felbermayr, G., J. Prat and H.-J. Schmerer (2011): "Globalization and labor market outcomes: Wage bargaining, search frictions, and firm heterogeneity". In: Journal of Economic theory 146.1, pp. 39-73.

GE, Y. (2007): "What do unions do in China?" In: SSRN Working Paper 1031084.

Gong, L. AND D. XIE (2006): "Factor mobility and dispersion in marginal products: A case on China". In: Frontiers of Economics in China 1.1, pp. 1-13.

Gouriéroux, C., A. Holly And A. Monfort (1981): "Kuhn-Tucker, likelihood ratio and Wald tests for nonlinear models with inequality constraints on the parameters". In: Journal of Econometrics 16.1, pp. 166-.

- (1982): "Likelihood Ratio Test, Wald Test, and Kuhn-Tucker Test in Linear Models with Inequality Constraints on the Regression Parameters". In: Econometrica 50.1, pp. 63-80.

Helpman, E. (2006): "Trade, FDI, and the Organization of Firms". In: Journal of Economic Literature 44.3, pp. 589-630.

Helpman, E., O. Itskhoki And S. Redding (2010): "Inequality and unemployment in a global economy". In: Econometrica 78.4, pp. 1239-1283.

Holz, C. A. (2009): "No razor's edge: Reexamining Alwyn Young's evidence for increasing interprovincial trade barriers in China". In: The Review of Economics and Statistics 91.3, pp. 599616.

Hsien, C.-T. And P. J. Klenow (2009): "Misallocation and Manufacturing TFP in China and India". In: The Quarterly Journal of Economics 124.4, p. 1403.

Huang, X. (2017): "Market Penetration, Institutional Niches and Job Searches in Reforming China". In: The China Quarterly 232, pp. 1070-1093. 
Kamal, F. And M. E. Lovely (2012): "Labor allocation in China: Implicit taxation of the heterogeneous non-state sector". In: CESifo Economic Studies 59.4, pp. 731-758.

Kamal, F., M. E. Lovely and D. Mitra (2015): "Trade Liberalization and Labor Shares in China". mimeo.

KNight, J. AND L. Shi (2005): "Wages, firm profitability and labor market segmentation in urban China". In: China Economic Review 16.3, pp. 205-228.

Kodde, D. A. ANd F. C. PAlm (1984): "Testing Equality and Inequality Restrictions A Distance Test". mimeo.

- (1986): "Wald Criteria for Jointly Testing Equality and Inequality Restrictions". In: Econometrica 54.5 , pp. $1243-1248$.

Kudo, A. (1963): "A Multivariate Analogue of the One-Sided Test". In: Biometrika 50.3/4, pp. 403418.

LARDy, N. R. (2004): Integrating China into the global economy. Brookings Institution Press.

Levinsohn, J. AND M. Melitz (2002): "Productivity in a differentiated products market equilibrium". mimeo.

LU, Y., Z. TAO AND Y. WANG (2010): "Union effects on performance and employment relations: Evidence from China". In: China Economic Review 21.1, pp. 202-210.

Lu, Y. AND L. YU (2015): "Trade liberalization and markup dispersion: evidence from China's WTO accession". In: American Economic Journal: Applied Economics 7.4, pp. 221-53.

MADDISON, A. et al. (1998): Chinese economic performance in the long run. OECD.

Meng, X. (2000): Labour market reform in China. Cambridge University Press.

Montagna, C. And A. Nocco (2013): "Unionization, international integration, and selection". In: Canadian Journal of Economics/Revue canadienne d'économique 46.1, pp. 23-45.

NeE, V. AND S. Opper (2012): Capitalism from Below: Markets and Institutional Change in China. Economics Books 9780674050204. Harvard University Press.

NÜESCH, P. E. (1964): "Multivariate tests of location for restricted alternatives". Diss. Math. ETH Zürich, Nr. 3508, 0000. Ref.: Saxer, W. ; Korref.: Dugué, D. PhD thesis.

- (1966): "On the Problem of Testing Location in Multivariate Populations for Restricted Alternatives". In: The Annals of Mathematical Statistics 37.1, pp. 113-119.

OECD (2005): OECD Economic Surveys: China 2005, p. 206.

Perkins, D. H. And T. G. Rawski (2008): "Forecasting China's economic growth to 2025". In: China's Great Economic Transformation. Ed. by L. Brandt and T. G. Rawski. Cambridge University Press, pp. 829-886.

Perlman, M. D. (1969): "One-Sided Testing Problems in Multivariate Analysis". In: The Annals of Mathematical Statistics 40.2, pp. 549-567.

Petrin, A. AND J. Sivadasan (2013): "Estimating lost output from allocative inefficiency, with an application to Chile and firing costs". In: Review of Economics and Statistics 95.1, pp. 286-301.

Robertson, T. And F. T. Wright (1983): "On Approximation of the Level Probabilities and Associated Distributions in Order Restricted Inference". In: Biometrika 70.3, pp. 597-606.

Robertson, T., F. Wright and R. Dykstra (1988): Order Restricted Statistical Inference. Wiley, New York. 
Shapiro, A. (1988): "Towards a Unified Theory of Inequality Constrained Testing in Multivariate Analysis". In: International Statistical Review / Revue Internationale de Statistique 56.1, pp. 49-62.

Shapiro, A. (1985): "Asymptotic Distribution of Test Statistics in the Analysis of Moment Structures Under Inequality Constraints". In: Biometrika 72.1, pp. 133-144.

Silvapulle, M. J. (1996): "On an F-type statistic for testing one-sided hypotheses and computation of chi-bar-squared weights". In: Statistics \& Probability Letters 28.2, pp. 137-141.

Silvapulle, M. J. And P. K. SEn (2011): Constrained statistical inference: Order, inequality, and shape constraints. Vol. 912. John Wiley \& Sons.

Siskind, V. (1976): "Approximate Probability Integrals and Critical Values for Bartholomew's Test for Ordered Means". In: Biometrika 63.3, pp. 647-654.

Tyвout, J. R. (2008): "Plant- and Firm-Level Evidence on "New" Trade Theories". In: Handbook of International Trade. Wiley-Blackwell. Chap. 13, pp. 388-415.

Wolak, F. A. (1987): "An Exact Test for Multiple Inequality and Equality Constraints in the Linear Regression Model". In: Journal of the American Statistical Association 82.399, pp. 782793.

Wolfe, P. (1959): "The Simplex Method for Quadratic Programming". In: Econometrica 27.3, pp. 382-398.

World Bank (2013): China 2030: Building a Modern, Harmonious, and Creative Society. The World Bank.

XIE, Y. AND X. WU (2008): "Danwei profitability and earnings inequality in urban China". In: The China Quarterly 195, pp. 558-581.

ZHANG, X. AND K.-Y. TAN (2007): "Incremental reform and distortions in China's product and factor markets". In: The World Bank Economic Review 21.2, pp. 279-299. 
Table 1: Classification procedure of firm-year regimes of competitiveness

\begin{tabular}{|c|c|c|}
\hline $\begin{array}{l}R=P C-P R \\
H_{0}: \mu_{i t}-1=\psi_{i t}=0\end{array}$ & against & $H_{1}: \mu_{i t}-1 \neq \psi_{i t} \neq 0$ \\
\hline$R=I C-P R$ & & \\
\hline$H_{01}: \mu_{i t}-1>0$ & against & $H_{11}: \mu_{i t}-1 \ngtr 0$ \\
\hline$H_{02}: \psi_{i t}=0$ & against & $H_{12}: \psi_{i t} \neq 0$ \\
\hline$R=P C-E B$ & & \\
\hline$H_{01}: \mu_{i t}-1=0$ & against & $H_{11}: \mu_{i t}-1 \neq 0$ \\
\hline$H_{02}: \psi_{i t}>0$ & against & $H_{12}: \psi_{i t} \ngtr 0$ \\
\hline$R=I C-E B$ & & \\
\hline$H_{01}: \mu_{i t}-1>0$ & against & $H_{11}: \mu_{i t}-1 \ngtr 0$ \\
\hline$H_{02}: \psi_{i t}>0$ & against & $H_{12}: \psi_{i t} \ngtr 0$ \\
\hline$R=P C-M O$ & & \\
\hline$H_{01}: \mu_{i t}-1=0$ & against & $H_{11}: \mu_{i t}-1 \neq 0$ \\
\hline$H_{02}: \psi_{i t}<0$ & against & $H_{12}: \psi_{i t} \nless 0$ \\
\hline$R=I C-M O$ & & \\
\hline$H_{01}: \mu_{i t}-1>0$ & against & $H_{11}: \mu_{i t}-1 \ngtr 0$ \\
\hline$H_{02}: \psi_{i t}<0$ & against & $H_{12}: \psi_{i t} \nless 0$ \\
\hline
\end{tabular}


Table 2: Descriptive statistics

\begin{tabular}{lccrrrr}
\hline \hline & Mean & Sd. & $Q_{1}$ & $Q_{2}$ & $Q_{3}$ & $\mathrm{~N}$ \\
\hline Real firm output growth rate $\Delta q_{i t}$ & .118 & .282 & -.046 & .105 & .275 & 258,045 \\
Labor growth rate $\Delta n_{i t}$ & .033 & .213 & -.054 & 0 & .111 & 258,117 \\
Materials growth rate $\Delta m_{i t}$ & .100 & .307 & -.085 & .090 & .277 & 258,112 \\
Capital growth rate $\Delta k_{i t}$ & .054 & .475 & -.105 & -.016 & .151 & 257,203 \\
$\alpha_{i t}^{N}\left(\Delta n_{i t}-\Delta k_{i t}\right)+\alpha_{i t}^{M}\left(\Delta m_{i t}-\Delta k_{i t}\right)$ & .032 & .468 & -.144 & .054 & .237 & 257,092 \\
$\alpha_{i t}^{N}\left(\Delta k_{i t}-\Delta n_{i t}\right)$ & .003 & .083 & -.018 & -.001 & .018 & 257,097 \\
Solow Residual $S R_{i t}{ }^{\text {a }}$ & .031 & .145 & -.041 & .029 & .103 & 257,025 \\
Labor share in total revenue $\alpha_{i t}^{N}$ & .146 & .106 & .070 & .121 & .193 & 315,543 \\
Materials share in total revenue $\alpha_{i t}^{M}$ & .771 & .097 & .721 & .780 & .832 & 315,694 \\
Capital share in total revenue ${ }^{\mathrm{b}}$ & .083 & .117 & .012 & .082 & .156 & 315,543 \\
Employment (FTEs) & 365 & 1,279 & 80 & 152 & 324 & 315,694 \\
\hline \hline
\end{tabular}

Note: ${ }^{\mathrm{a}} S R_{i t}=\Delta q_{i t}-\alpha_{i t}^{N} \Delta n_{i t}-\alpha_{i t}^{M} \Delta m_{i t}-\left(1-\alpha_{i t}^{N}-\alpha_{i t}^{M}\right) \Delta k_{i t}$, $\mathrm{b}\left(1-\alpha_{i t}^{N}-\alpha_{i t}^{M}\right)$. 
Table 3: Time variation in dominant regimes of competitiveness by industry

\begin{tabular}{|c|c|c|c|c|c|c|c|c|}
\hline & & 2000 & 2001 & 2002 & 2003 & 2004 & 2005 & 2006 \\
\hline 1 & Food Proc. & $I C-E B$ & $I C-E B$ & $I C-E B$ & $I C-E B$ & $I C-E B$ & $I C-E B$ & $I C-E B$ \\
\hline 2 & Food & $I C-E B$ & $I C-E B$ & $I C-E B$ & $I C-E B$ & $I C-E B$ & $I C-E B$ & $I C-E B$ \\
\hline 3 & Bev. \& Tob. & $I C-E B$ & $I C-E B$ & $I C-E B$ & $I C-E B$ & $I C-E B$ & $I C-E B$ & $I C-E B$ \\
\hline 4 & Text & $I C-E B$ & $I C-E B$ & $I C-E B$ & $I C-E B$ & $I C-E B$ & $I C-E B$ & $I C-E B$ \\
\hline 5 & Wear & $I C-E B$ & $I C-E B$ & $I C-E B$ & $I C-E B$ & $I C-E B$ & $I C-E B$ & $I C-E B$ \\
\hline 6 & Leather & $I C-E B$ & $I C-E B$ & $I C-E B$ & $I C-E B$ & $I C-E B$ & $I C-E B$ & $I C-E B$ \\
\hline 7 & Wood & $I C-M O$ & $I C-M O$ & $I C-M O$ & $I C-M O$ & $I C-M O$ & $I C-M O$ & $I C-M O$ \\
\hline 8 & Furn. & $I C-E B$ & $I C-E B$ & $I C-E B$ & $I C-E B$ & $I C-M O$ & $I C-M O$ & $I C-M O$ \\
\hline 9 & Paper & $I C-E B$ & $I C-E B$ & $I C-E B$ & $I C-E B$ & $I C-E B$ & $I C-E B$ & $I C-E B$ \\
\hline 10 & Print. & $I C-E B$ & $I C-E B$ & $I C-E B$ & $I C-E B$ & $I C-E B$ & $I C-E B$ & $I C-E B$ \\
\hline 11 & Petrol & $I C-E B$ & $I C-E B$ & $I C-E B$ & $I C-E B$ & $I C-E B$ & $I C-E B$ & $I C-E B$ \\
\hline 12 & Chem. & $I C-E B$ & $I C-E B$ & $I C-E B$ & $I C-E B$ & $I C-E B$ & $I C-E B$ & $I C-E B$ \\
\hline 13 & Pharma. & $I C-E B$ & $I C-E B$ & $I C-E B$ & $I C-E B$ & $I C-E B$ & $I C-E B$ & $I C-E B$ \\
\hline 14 & Chem. Fiber & $I C-E B$ & $I C-M O$ & $I C-E B$ & $I C-E B$ & $I C-M O$ & $I C-M O$ & $I C-E B$ \\
\hline 15 & Rubber & $I C-E B$ & $I C-E B$ & $I C-E B$ & $I C-E B$ & $I C-E B$ & $I C-E B$ & $I C-E B$ \\
\hline 16 & Plastic & $I C-E B$ & $I C-E B$ & $I C-E B$ & $I C-E B$ & $I C-E B$ & $I C-E B$ & $I C-E B$ \\
\hline 17 & Minerals & $I C-E B$ & $I C-E B$ & $I C-E B$ & $I C-E B$ & $I C-E B$ & $I C-E B$ & $I C-E B$ \\
\hline 18 & Fer. Metal & $I C-E B$ & $I C-E B$ & $I C-E B$ & $I C-E B$ & $I C-E B$ & $I C-E B$ & $I C-E B$ \\
\hline 19 & Nonfer. Metal & $I C-M O$ & $I C-M O$ & $I C-M O$ & $I C-M O$ & $I C-M O$ & $I C-M O$ & $I C-M O$ \\
\hline 20 & Fab. Metal & $I C-E B$ & $I C-E B$ & $I C-E B$ & $I C-E B$ & $I C-E B$ & $I C-E B$ & $I C-E B$ \\
\hline 21 & Gen. Mach. & $I C-E B$ & $I C-E B$ & $I C-E B$ & $I C-E B$ & $I C-E B$ & $I C-E B$ & $I C-E B$ \\
\hline 22 & Spec. Mach. & $I C-E B$ & $I C-E B$ & $I C-E B$ & $I C-E B$ & $I C-E B$ & $I C-E B$ & $I C-E B$ \\
\hline 23 & Transport & $I C-E B$ & $I C-E B$ & $I C-E B$ & $I C-E B$ & $I C-E B$ & $I C-E B$ & $I C-E B$ \\
\hline 24 & Elec. Mach. & $I C-E B$ & $I C-E B$ & $I C-E B$ & $I C-E B$ & $I C-E B$ & $I C-E B$ & $I C-E B$ \\
\hline 25 & Comp. & $I C-E B$ & $I C-E B$ & $I C-E B$ & $I C-E B$ & $I C-E B$ & $I C-E B$ & $I C-E B$ \\
\hline 26 & Instr. & $I C-E B$ & $I C-E B$ & $I C-E B$ & $I C-E B$ & $I C-E B$ & $I C-E B$ & $I C-E B$ \\
\hline 27 & Educ. \& Sport & $I C-E B$ & $I C-E B$ & $I C-E B$ & $I C-E B$ & $I C-E B$ & $I C-E B$ & $I C-E B$ \\
\hline 28 & NEC & $I C-E B$ & $I C-E B$ & $I C-E B$ & $I C-E B$ & $I C-E B$ & $I C-E B$ & $I C-E B$ \\
\hline
\end{tabular}


Table 4: Prevailing regimes of competitiveness at the industry level

\begin{tabular}{|c|c|c|c|c|c|c|c|c|}
\hline IND & Industry & $P C-P R$ & $I C-P R$ & $P C-E B$ & $I C-E B$ & $P C-M O$ & $I C-M O$ & Dominant regime \\
\hline 9 & Paper & 0.01 & 0.10 & 0.67 & 0.99 & 0.02 & 0.06 & $I C-E B$ \\
\hline 10 & Print. & 0.02 & 0.06 & 0.48 & 0.99 & 0.02 & 0.05 & $I C-E B$ \\
\hline 15 & Rubber & 0.03 & 0.32 & 0.89 & 0.99 & 0.04 & 0.20 & $I C-E B$ \\
\hline 21 & Gen. Mach. & 0.01 & 0.02 & 0.16 & 0.98 & 0.02 & 0.02 & $I C-E B$ \\
\hline 2 & Food & 0.02 & 0.09 & 0.66 & 0.96 & 0.05 & 0.09 & $I C-E B$ \\
\hline 5 & Wear & 0.02 & 0.04 & 0.16 & 0.96 & 0.03 & 0.03 & $I C-E B$ \\
\hline 17 & Minerals & 0.01 & 0.08 & 0.28 & 0.95 & 0.03 & 0.09 & $I C-E B$ \\
\hline 25 & Comp. & 0.00 & 0.05 & 0.53 & 0.95 & 0.01 & 0.03 & $I C-E B$ \\
\hline 27 & Educ. \& Sport & 0.02 & 0.20 & 0.63 & 0.95 & 0.07 & 0.18 & $I C-E B$ \\
\hline 22 & Spec. Mach. & 0.01 & 0.04 & 0.43 & 0.94 & 0.05 & 0.07 & $I C-E B$ \\
\hline 16 & Plastic & 0.01 & 0.08 & 0.40 & 0.90 & 0.05 & 0.10 & $I C-E B$ \\
\hline 18 & Fer. Metal & 0.01 & 0.31 & 0.89 & 0.90 & 0.11 & 0.34 & $I C-E B$ \\
\hline 11 & Petrol & 0.01 & 0.55 & 0.77 & 0.88 & 0.13 & 0.59 & $I C-E B$ \\
\hline 4 & Text & 0.02 & 0.14 & 0.22 & 0.87 & 0.12 & 0.22 & $I C-E B$ \\
\hline 20 & Fab. Metal & 0.02 & 0.16 & 0.39 & 0.87 & 0.12 & 0.24 & $I C-E B$ \\
\hline 6 & Leather & 0.05 & 0.21 & 0.47 & 0.86 & 0.18 & 0.30 & $I C-E B$ \\
\hline 23 & Transport & 0.01 & 0.07 & 0.40 & 0.81 & 0.12 & 0.16 & $I C-E B$ \\
\hline 28 & NEC & 0.02 & 0.16 & 0.46 & 0.81 & 0.11 & 0.20 & $I C-E B$ \\
\hline 12 & Chem. & 0.01 & 0.10 & 0.50 & 0.80 & 0.15 & 0.22 & $I C-E B$ \\
\hline 13 & Pharma. & 0.04 & 0.25 & 0.33 & 0.76 & 0.25 & 0.42 & $I C-E B$ \\
\hline 14 & Chem. Fiber & 0.09 & 0.57 & 0.73 & 0.76 & 0.32 & 0.68 & $I C-E B$ \\
\hline 1 & Food Proc. & 0.03 & 0.30 & 0.49 & 0.75 & 0.27 & 0.47 & $I C-E B$ \\
\hline 24 & Elec. Mach. & 0.02 & 0.16 & 0.44 & 0.75 & 0.14 & 0.25 & $I C-E B$ \\
\hline 3 & Bev. \& Tob. & 0.03 & 0.30 & 0.47 & 0.72 & 0.30 & 0.51 & $I C-E B$ \\
\hline 26 & Instr. & 0.08 & 0.19 & 0.47 & 0.66 & 0.40 & 0.49 & $I C-E B$ \\
\hline 7 & Wood & 0.06 & 0.23 & 0.42 & 0.46 & 0.57 & 0.70 & $I C-M O$ \\
\hline 19 & Nonfer. Metal & 0.02 & 0.15 & 0.28 & 0.42 & 0.51 & 0.62 & $I C-M O$ \\
\hline 8 & Furn. & 0.06 & 0.22 & 0.45 & 0.58 & 0.46 & 0.58 & $I C-M O$ \\
\hline
\end{tabular}


Table 5: WTO entry effect on regimes of competitiveness at the industry level

\begin{tabular}{|c|c|c|c|c|c|c|c|}
\hline IND & Industry & $P C-P R$ & $\overline{I C-P R}$ & $P C-E B$ & $P C-M O$ & $\overline{I C-M O}$ & $\overline{I C-E B}$ \\
\hline 1 & Food Proc. & -0.08 & -0.01 & 0.00 & -0.13 & -0.05 & - \\
\hline 2 & Food & -0.02 & 0.00 & -0.04 & -0.05 & -0.05 & - \\
\hline 3 & Bev. \& Tob. & -0.15 & -0.03 & -0.08 & $-0.33^{*}$ & $-0.17^{\ddagger}$ & - \\
\hline 4 & Text & -0.01 & -0.00 & 0.00 & -0.01 & -0.01 & - \\
\hline 5 & Wear & 0.02 & 0.00 & -0.09 & 0.02 & 0.01 & - \\
\hline 6 & Leather & -0.02 & 0.04 & -0.00 & -0.04 & 0.01 & - \\
\hline 9 & Paper & -0.00 & -0.00 & 0.09 & -0.01 & -0.02 & - \\
\hline 10 & Print. & 0.00 & -0.02 & 0.00 & 0.00 & 0.01 & - \\
\hline 11 & Petrol & 0.03 & -0.04 & $-0.15^{\ddagger}$ & 0.06 & 0.06 & - \\
\hline 12 & Chem. & 0.08 & 0.07 & 0.13 & 0.15 & 0.13 & - \\
\hline 13 & Pharma. & 0.02 & 0.01 & 0.01 & 0.01 & 0.01 & - \\
\hline 14 & Chem. Fiber & 0.01 & 0.02 & -0.03 & 0.01 & $0.08^{\dagger}$ & - \\
\hline 15 & Rubber & -0.00 & 0.10 & $0.04^{\dagger}$ & 0.01 & 0.03 & - \\
\hline 16 & Plastic & -0.02 & 0.00 & 0.08 & -0.01 & 0.00 & - \\
\hline 17 & Minerals & 0.01 & -0.00 & -0.02 & 0.01 & -0.01 & - \\
\hline 18 & Fer. Metal & 0.05 & $0.29^{*}$ & 0.02 & 0.10 & $0.30^{*}$ & - \\
\hline 20 & Fab. Metal & -0.02 & -0.02 & 0.01 & -0.07 & -0.08 & - \\
\hline 21 & Gen. Mach. & 0.00 & 0.00 & -0.01 & 0.00 & 0.00 & - \\
\hline 22 & Spec. Mach. & 0.07 & 0.05 & 0.07 & 0.11 & 0.10 & - \\
\hline 23 & Transport & 0.10 & 0.09 & 0.14 & 0.14 & 0.14 & - \\
\hline 24 & Elec. Mach. & -0.00 & -0.05 & 0.04 & 0.05 & -0.01 & - \\
\hline 25 & Comp. & 0.05 & 0.04 & -0.01 & 0.05 & 0.04 & - \\
\hline 26 & Instr. & 0.09 & 0.10 & 0.03 & 0.11 & 0.12 & - \\
\hline 27 & Educ. \& Sport & -0.03 & 0.03 & 0.06 & -0.06 & -0.01 & - \\
\hline 28 & NEC & -0.06 & -0.10 & -0.04 & -0.05 & -0.06 & - \\
\hline 7 & Wood & 0.01 & -0.00 & -0.01 & -0.02 & - & -0.02 \\
\hline 8 & Furn. & -0.15 & -0.15 & $-0.25^{\ddagger}$ & $-0.04^{\ddagger}$ & - & $-0.29^{*}$ \\
\hline 19 & Nonfer. Metal & -0.02 & -0.03 & -0.11 & 0.02 & - & -0.08 \\
\hline
\end{tabular}

* denotes a regime that displays a difference-in-difference change exceeding 25 percentage points in absolute value. ${ }^{\dagger}$ denotes a regime that is more than 10 percentage points apart from the dominant regime prior to WTO entry and less than 10 percentage points apart after WTO entry. ${ }^{\ddagger}$ denotes a regime that is less than 10 percentage points apart from the dominant regime prior to WTO entry and more than 10 percentage points apart after WTO entry. 
Table 6: Extensive margin analysis: WTO impact on switching away from an imperfectly competitive product/labor market setting in the pre-WTO period: Probit, OLS and IV estimates

\begin{tabular}{|c|c|c|c|c|c|c|c|c|c|}
\hline & \multicolumn{2}{|c|}{$\bar{P}(I C$-switch } & $\overline{x)}$ & \multicolumn{2}{|c|}{$\mathbb{P}(E B$-switch } & $\overline{x)}$ & \multicolumn{2}{|c|}{$\mathbb{P}(M O$-switch } & $\overline{x)}$ \\
\hline & Probit & OLS & IV & Probit & OLS & IV & Probit & OLS & IV \\
\hline L1.input tariff & $\begin{array}{l}.002 \\
(.002)\end{array}$ & $\begin{array}{l}.003 \\
(.002)\end{array}$ & $\begin{array}{l}.003 \\
(.002)\end{array}$ & $\begin{array}{l}.032^{* *} \\
(.015)\end{array}$ & $\begin{array}{l}.041^{* *} \\
(.021)\end{array}$ & $\begin{array}{l}.038^{*} \\
(.020)\end{array}$ & $\begin{array}{l}.203^{* *} \\
(.095)\end{array}$ & $\begin{array}{l}.238^{* *} \\
(.096)\end{array}$ & $\begin{array}{l}.267^{* * *} \\
(.098)\end{array}$ \\
\hline L1.output tariff & $\begin{array}{l}-.000 \\
(.000)\end{array}$ & $\begin{array}{l}-.000 \\
(.000)\end{array}$ & $\begin{array}{l}-.000 \\
(.000)\end{array}$ & $\begin{array}{l}-.006 \\
(.004)\end{array}$ & $\begin{array}{c}-.007^{*} \\
(.004)\end{array}$ & $\begin{array}{l}-.007^{*} \\
(.004)\end{array}$ & $\begin{array}{c}-.089^{* * *} \\
(.033)\end{array}$ & $\begin{array}{c}-.079^{* * *} \\
(.025)\end{array}$ & $\begin{array}{c}-.090^{* * *} \\
(.025)\end{array}$ \\
\hline $\begin{array}{l}\text { Year fixed effects } \\
\text { Observations }\end{array}$ & $\begin{array}{c}\text { Yes } \\
84223\end{array}$ & $\begin{array}{c}\text { Yes } \\
84223\end{array}$ & $\begin{array}{c}\text { Yes } \\
84223\end{array}$ & $\begin{array}{c}\text { Yes } \\
112186\end{array}$ & $\begin{array}{c}\text { Yes } \\
112186\end{array}$ & $\begin{array}{c}\text { Yes } \\
112186\end{array}$ & $\begin{array}{l}\text { Yes } \\
6440\end{array}$ & $\begin{array}{c}\text { Yes } \\
6440\end{array}$ & $\begin{array}{l}\text { Yes } \\
6440\end{array}$ \\
\hline
\end{tabular}

Standard errors in parentheses are clustered at the 4-digit industry-year level.

${ }^{*} p<0.10,{ }^{* *} p<0.05,{ }^{* * *} p<0.01$. 
Table 7: Intensive margin analysis: WTO impact on the degree of firms' product/labor market power: OLS and IV estimates

\begin{tabular}{|c|c|c|c|c|c|c|}
\hline & \multicolumn{2}{|c|}{$\ln \widehat{\mu}$} & \multicolumn{2}{|c|}{$\ln \left(\frac{\widehat{\phi}}{1-\widehat{\phi}}\right)$} & \multicolumn{2}{|c|}{$\ln \left(\widehat{\varepsilon}_{W}^{N}\right)$} \\
\hline & OLS & IV & OLS & IV & OLS & IV \\
\hline$\overline{\text { L1.input tariff }}$ & $\begin{array}{c}-.716^{* *} \\
(.310)\end{array}$ & $\begin{array}{l}-.780^{*} \\
(.422)\end{array}$ & $\begin{array}{l}-4.376^{*} \\
(2.356)\end{array}$ & $\begin{array}{l}-4.437 \\
(3.084)\end{array}$ & $\begin{array}{c}-7.706^{* * *} \\
(2.248)\end{array}$ & $\begin{array}{c}-7.498^{* * *} \\
(2.386)\end{array}$ \\
\hline L1.output tariff & $\begin{array}{l}.172 \\
(.156)\end{array}$ & $\begin{array}{l}.116 \\
(.132)\end{array}$ & $\begin{array}{l}-.718 \\
(.805)\end{array}$ & $\begin{array}{l}-.176 \\
(.714)\end{array}$ & $\begin{array}{l}.225 \\
(.794)\end{array}$ & $\begin{array}{l}-.115 \\
(.842)\end{array}$ \\
\hline Firm fixed effects & Yes & Yes & Yes & Yes & Yes & Yes \\
\hline Year fixed effects & Yes & Yes & Yes & Yes & Yes & Yes \\
\hline Inverse Mills ratio & Yes & Yes & Yes & Yes & Yes & Yes \\
\hline Adjusted- $R^{2}$ & .034 & .033 & .025 & .024 & .038 & .037 \\
\hline Observations & 153368 & 153368 & 170288 & 170288 & 19151 & 19151 \\
\hline
\end{tabular}

Standard errors in parentheses are clustered at the 4-digit industry-year level.

${ }^{*} p<0.10,{ }^{* *} p<0.05,{ }^{* * *} p<0.01$. 
Table 8: Intensive margin analysis: WTO impact on the degree of firms' product/labor market power, conditional on being a stayer: OLS and IV estimates

\begin{tabular}{|c|c|c|c|c|c|c|}
\hline & \multicolumn{2}{|c|}{$\ln \widehat{\mu}$} & \multicolumn{2}{|c|}{$\ln \left(\frac{\widehat{\phi}}{1-\widehat{\phi}}\right)$} & \multicolumn{2}{|c|}{$\ln \left(\widehat{\varepsilon}_{W}^{N}\right)$} \\
\hline & OLS & IV & OLS & IV & OLS & IV \\
\hline$\overline{\text { L1.input tariff }}$ & $\begin{array}{c}-.675^{* *} \\
(.303)\end{array}$ & $\begin{array}{l}-.658 \\
(.422)\end{array}$ & $\begin{array}{c}-2.838 \\
(1.813)\end{array}$ & $\begin{array}{c}-2.758 \\
(2.278)\end{array}$ & $\begin{array}{c}-7.587^{* * *} \\
(1.679)\end{array}$ & $\begin{array}{c}-7.620^{* * *} \\
(1.692)\end{array}$ \\
\hline L1.output tariff & $\begin{array}{l}-.009 \\
(.108)\end{array}$ & $\begin{array}{l}-.016 \\
(.113)\end{array}$ & $\begin{array}{l}-.052 \\
(.475)\end{array}$ & $\begin{array}{l}.109 \\
(.550)\end{array}$ & $\begin{array}{c}.227 \\
(.635) \\
\end{array}$ & $\begin{array}{l}-.130 \\
(.585) \\
\end{array}$ \\
\hline Firm fixed effects & Yes & Yes & Yes & Yes & Yes & Yes \\
\hline Year fixed effects & Yes & Yes & Yes & Yes & Yes & Yes \\
\hline Inverse Mills ratio & Yes & Yes & Yes & Yes & Yes & Yes \\
\hline Adjusted- $R^{2}$ & .040 & .040 & .021 & .021 & .058 & .057 \\
\hline Observations & 84197 & 84197 & 91076 & 91076 & 5815 & 5815 \\
\hline
\end{tabular}

Standard errors in parentheses are clustered at the 4-digit industry-year level.

${ }^{*} p<0.10,{ }^{* *} p<0.05,{ }^{* * *} p<0.01$. 
Figure 1: Average change in regime of competitiveness at the industry level and within-industry variation

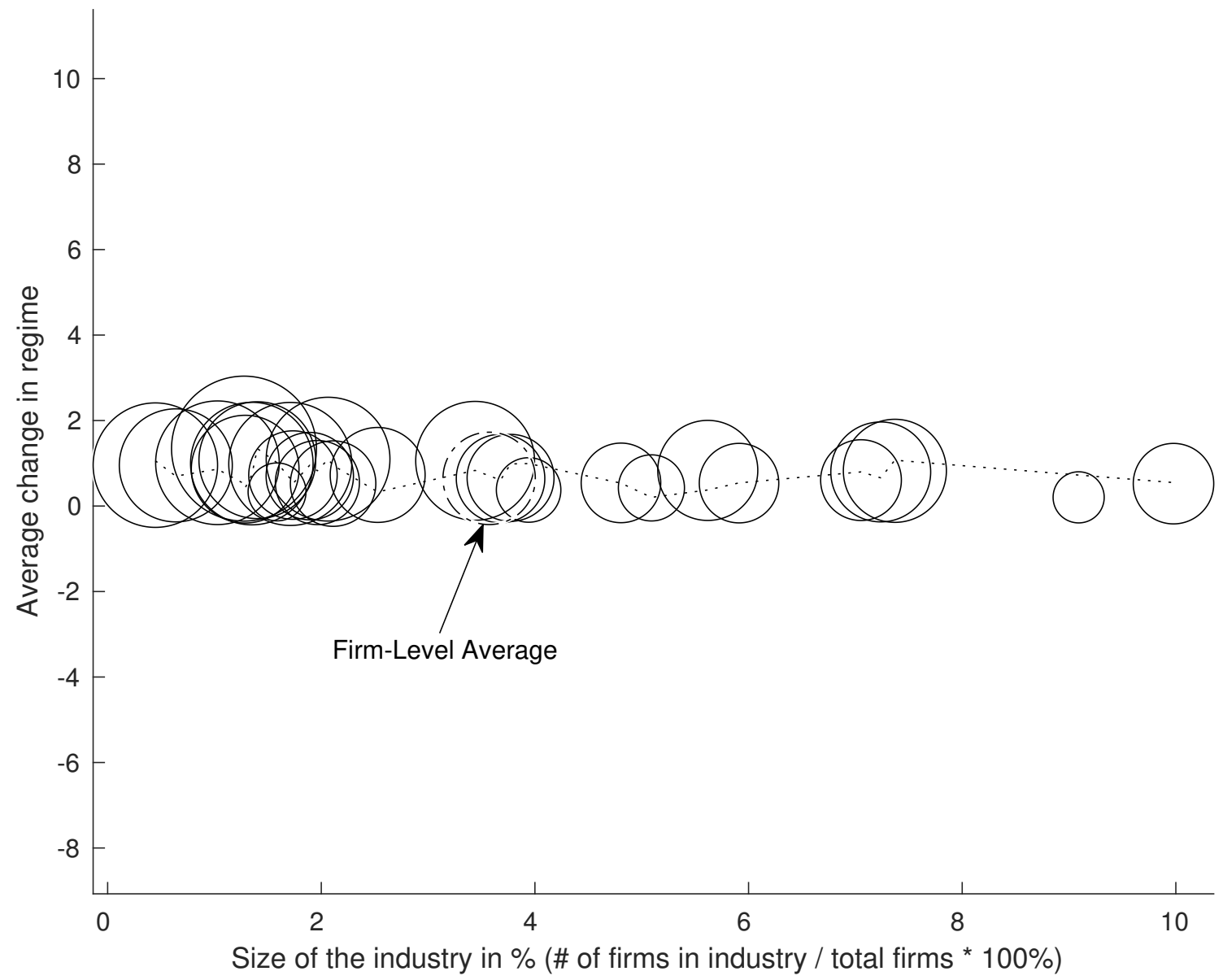

The average change in regime of competitiveness at the industry level is shown as the center of each circle. The average change is measured as the difference in regime between the first and last year available for each firm, then aggregated to the industry level. Variation in the change in regime of competitiveness, measured as the standard deviation, is visualized as the radius of each circle. The dashed circle denotes the firm-level average. Industries are ranked according to their size, which is measured as the fraction of the total number of firms belonging to the industry. 
Figure 2: Composition of inconclusiveness at the industry level

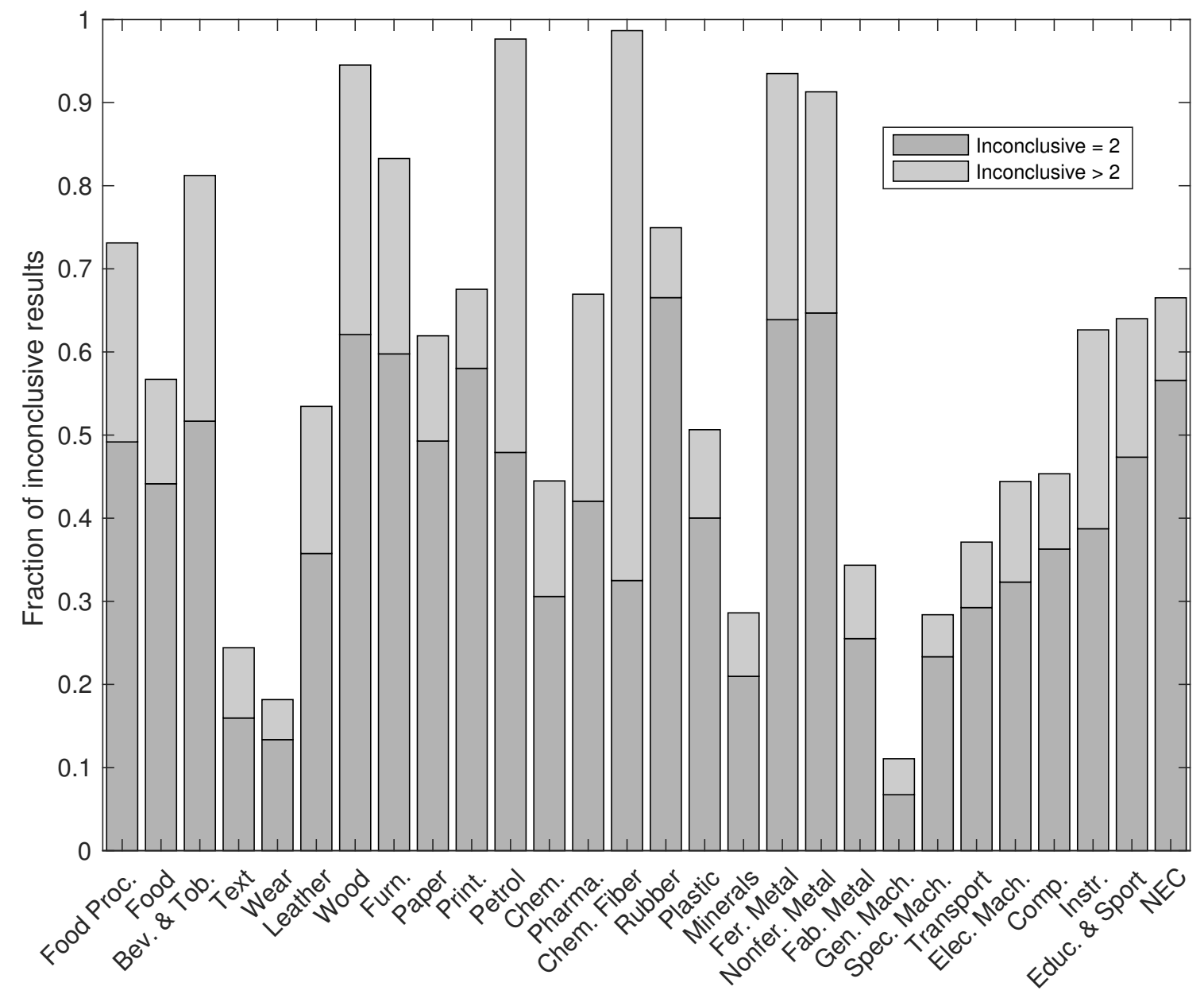

The composition of the inconclusiveness at the industry level is shown in a bar graph. Inconclusiveness is split into to mild inconclusiveness (inconclusiveness between two regimes) and severe inconclusiveness (inconclusiveness between more than two regimes). 
Figure 3: Relationship between inconclusiveness and industry size

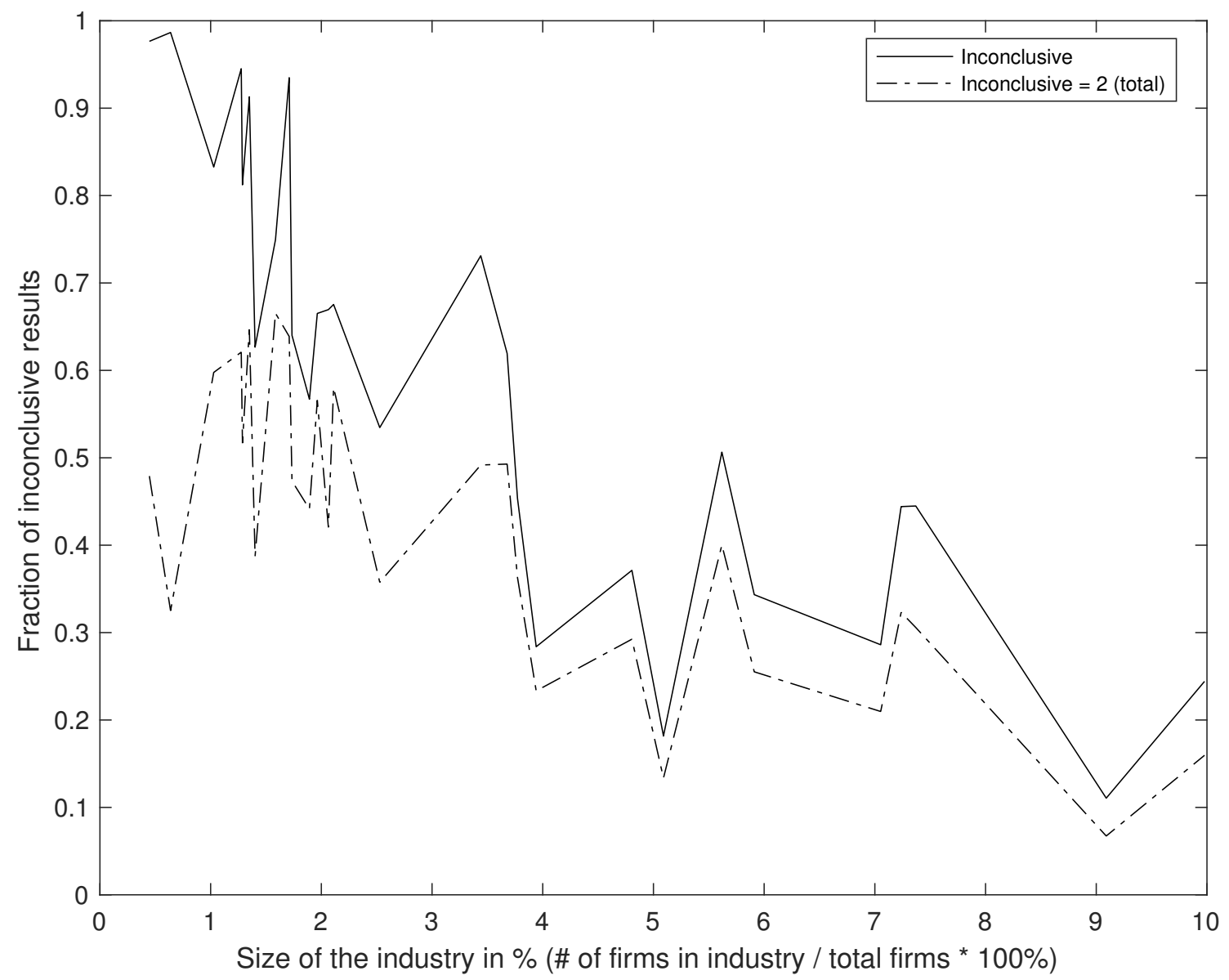

The relationship between inconclusiveness and industry size is shown for both total inconclusiveness and inconclusiveness between two regimes. The proportion of inconclusiveness cases between two regimes relative to the total number of inconclusive cases is also depicted. 
Figure 4: Relationship between conditional inconclusiveness and industry size

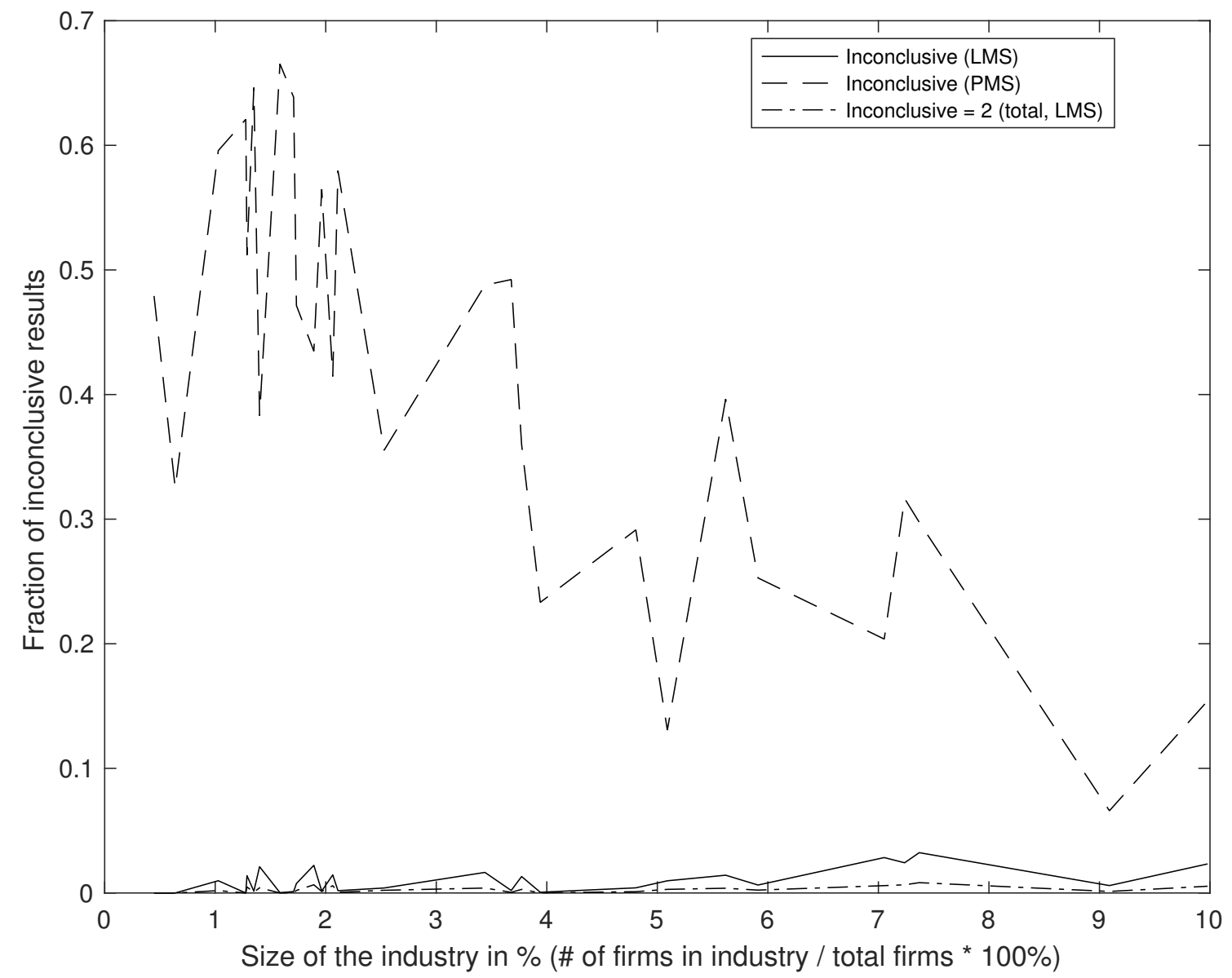

Conditional inconclusiveness is defined as inconclusiveness based on PMS ( $L M S)$, conditional on being conclusive on $L M S(P M S)$. When we restrict the conditional inconclusiveness to two regimes, we only show conditional inconclusiveness for the $L M S$, as for the $P M S$ it is identical to the unrestricted conditional inconclusiveness. 
Appendix

Table A.1: Panel structure

\begin{tabular}{|c|c|c|c|c|}
\hline \# of Participations ${ }^{\mathrm{a}}$ & \# Obs. & $\%$ & \# Firms & $\%$ \\
\hline 4 & 82,536 & 26.14 & 20,634 & 35.84 \\
\hline 5 & 67,720 & 21.45 & 13,544 & 23.52 \\
\hline 6 & 52,476 & 16.62 & 8,746 & 15.19 \\
\hline 7 & 29,834 & 9.45 & 4,262 & 7.40 \\
\hline 8 & 83,128 & 26.33 & 10,391 & 18.05 \\
\hline Total & 315,694 & 100.00 & 57,577 & 100.00 \\
\hline
\end{tabular}

Note: ${ }^{a}$ Median number of observations per firm: 5 .

Table A.2: Industry composition

\begin{tabular}{|c|c|c|c|}
\hline IND & Industry & \# Firms & \# Obs \\
\hline 1 & Food Proc. & 2,059 & 10,959 \\
\hline 2 & Food & 1,080 & 5,989 \\
\hline 3 & Bev. \& Tob. & 714 & 4,034 \\
\hline 4 & Textile & 5,861 & 31,572 \\
\hline 5 & Wear & 3,037 & 16,176 \\
\hline 6 & Leather & 1,529 & 8,055 \\
\hline 7 & Wood & 804 & 4,167 \\
\hline 8 & Furniture & 635 & 3,298 \\
\hline 9 & Paper & 2,085 & 11,577 \\
\hline 10 & Printing & 1,158 & 6,630 \\
\hline 11 & Petroleum & 256 & 1,419 \\
\hline 12 & Chemicals & 4,091 & 23,103 \\
\hline 13 & Pharma. & 1,123 & 6,449 \\
\hline 14 & Chem. Fibres & 371 & 2,012 \\
\hline 15 & Rubber & 886 & 4,968 \\
\hline 16 & Plastic & 3,247 & 17,744 \\
\hline 17 & Minerals & 4,090 & 22,299 \\
\hline 18 & Fer. Metal & 994 & 5,408 \\
\hline 19 & Nonfer. Metal & 783 & 4,272 \\
\hline 20 & Fab. Metal & 3,441 & 18,683 \\
\hline 21 & Gen. Mach. & 5,115 & 28,531 \\
\hline 22 & Spec. Mach. & 2,275 & 12,432 \\
\hline 23 & Transport. & 2,713 & 15,104 \\
\hline 24 & Elec. Mach. & 4,090 & 22,740 \\
\hline 25 & Computing & 2,146 & 11,903 \\
\hline 26 & Meas. Instr. & 811 & 4,432 \\
\hline 27 & Educ. \& Sport & 996 & 5,470 \\
\hline 28 & $\mathrm{NEC}^{\mathrm{a}}$ & 1,187 & 6,268 \\
\hline Total & & 57,577 & 315,694 \\
\hline
\end{tabular}

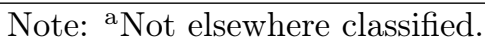


Table A.3: Average change in regime of competitiveness at the industry level and within-industry variation

\begin{tabular}{llccc}
\hline \hline IND & Industry & Size & Average Change & Variation (sd) \\
\hline 1 & Food Proc. & 8.60 & 1.06 & 1.39 \\
2 & Food & 4.73 & 0.70 & 1.02 \\
3 & Bev. \& Tob. & 3.22 & 0.86 & 1.26 \\
4 & Text & 24.95 & 0.52 & 0.94 \\
5 & Wear & 12.73 & 0.42 & 0.77 \\
6 & Leather & 6.32 & 0.73 & 1.11 \\
7 & Wood & 3.19 & 1.34 & 1.70 \\
8 & Furn. & 2.57 & 1.01 & 1.45 \\
9 & Paper & 9.20 & 0.64 & 1.04 \\
10 & Print. & 5.28 & 0.53 & 1.00 \\
11 & Petrol & 1.12 & 0.96 & 1.46 \\
12 & Chem. & 18.42 & 0.82 & 1.21 \\
13 & Pharma. & 5.16 & 1.10 & 1.45 \\
14 & Chem. Fiber & 1.60 & 0.95 & 1.32 \\
15 & Rubber & 3.96 & 0.33 & 0.68 \\
16 & Plastic & 14.05 & 0.83 & 1.17 \\
17 & Minerals & 17.63 & 0.61 & 0.94 \\
18 & Fer. Metal & 4.27 & 0.98 & 1.44 \\
19 & Nonfer. Metal & 3.37 & 0.99 & 1.43 \\
20 & Fab. Metal & 14.78 & 0.54 & 0.93 \\
21 & Gen. Mach. & 22.73 & 0.20 & 0.60 \\
22 & Spec. Mach. & 9.85 & 0.38 & 0.75 \\
23 & Transport & 12.01 & 0.54 & 0.93 \\
24 & Elec. Mach. & 18.09 & 0.80 & 1.17 \\
25 & Comp. & 9.43 & 0.66 & 1.02 \\
26 & Instr. & 3.50 & 1.07 & 1.37 \\
27 & Educ. \& Sport & 4.34 & 0.72 & 1.03 \\
28 & NEC & 4.91 & 0.55 & 0.98 \\
& & & & \\
Firm-level avg. & 8.93 & 0.65 & 1.08 \\
\hline \hline
\end{tabular}

This table reports the underlying numbers of Figure 1. For each of the 28 industries, it reports the number of average changes in regime of competitiveness and within-industry variation (standard deviation) of the average change. The size of each industry is determined as the fraction of the total number of firms operating in each particular industry. 
Figure A.1: Composition of inconclusiveness at the industry level for subset of inconclusive cases between two or three regimes

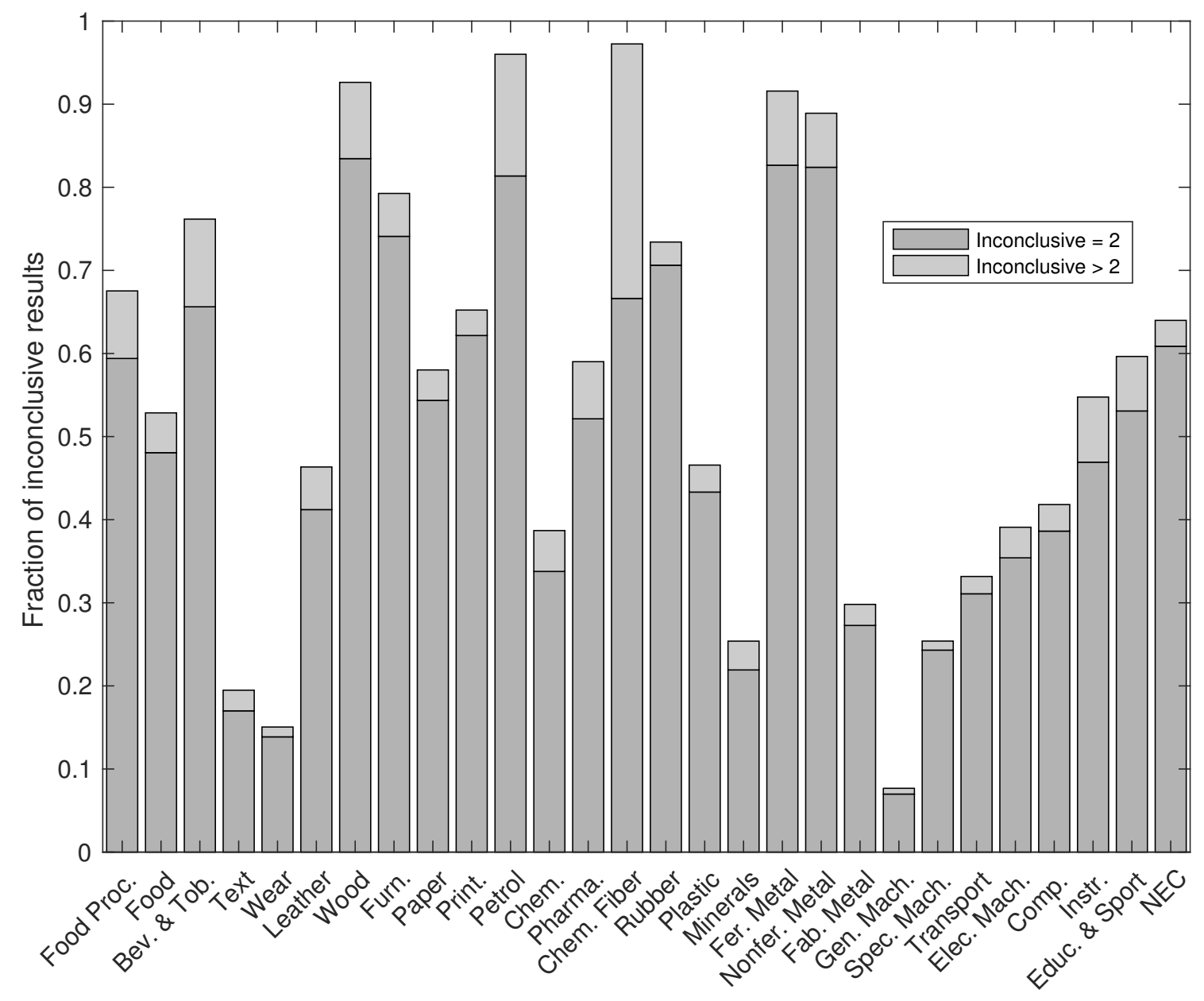

The composition of the inconclusiveness at the industry level is shown in a bar graph for observations with inconclusiveness between two or three regimes. Inconclusiveness is split into mild inconclusiveness (inconclusiveness between two regimes) and severe inconclusiveness (inconclusiveness between more than two regimes). 
Figure A.2: Relationship between inconclusiveness and industry size for subset of inconclusive cases between two or three regimes

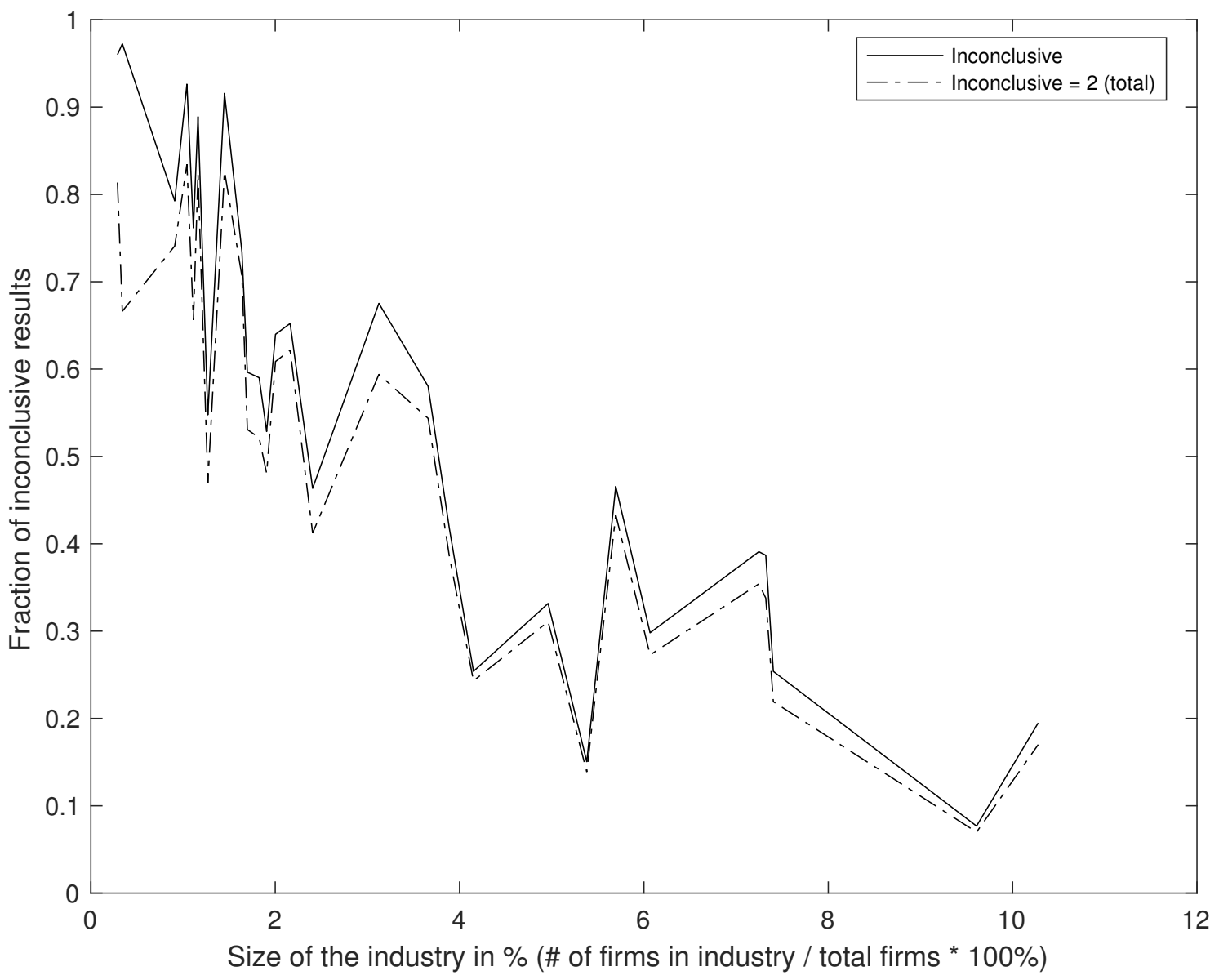

The relationship between inconclusiveness and industry size is shown for both total inconclusiveness and inconclusiveness between two regimes for the subset of inconclusive cases between two or three regimes. The proportion of inconclusiveness cases between two regimes relative to the total number of inconclusive cases is also depicted. 
Figure A.3: Relationship between conditional inconclusiveness and industry size for subset of inconclusive cases between two or three regimes

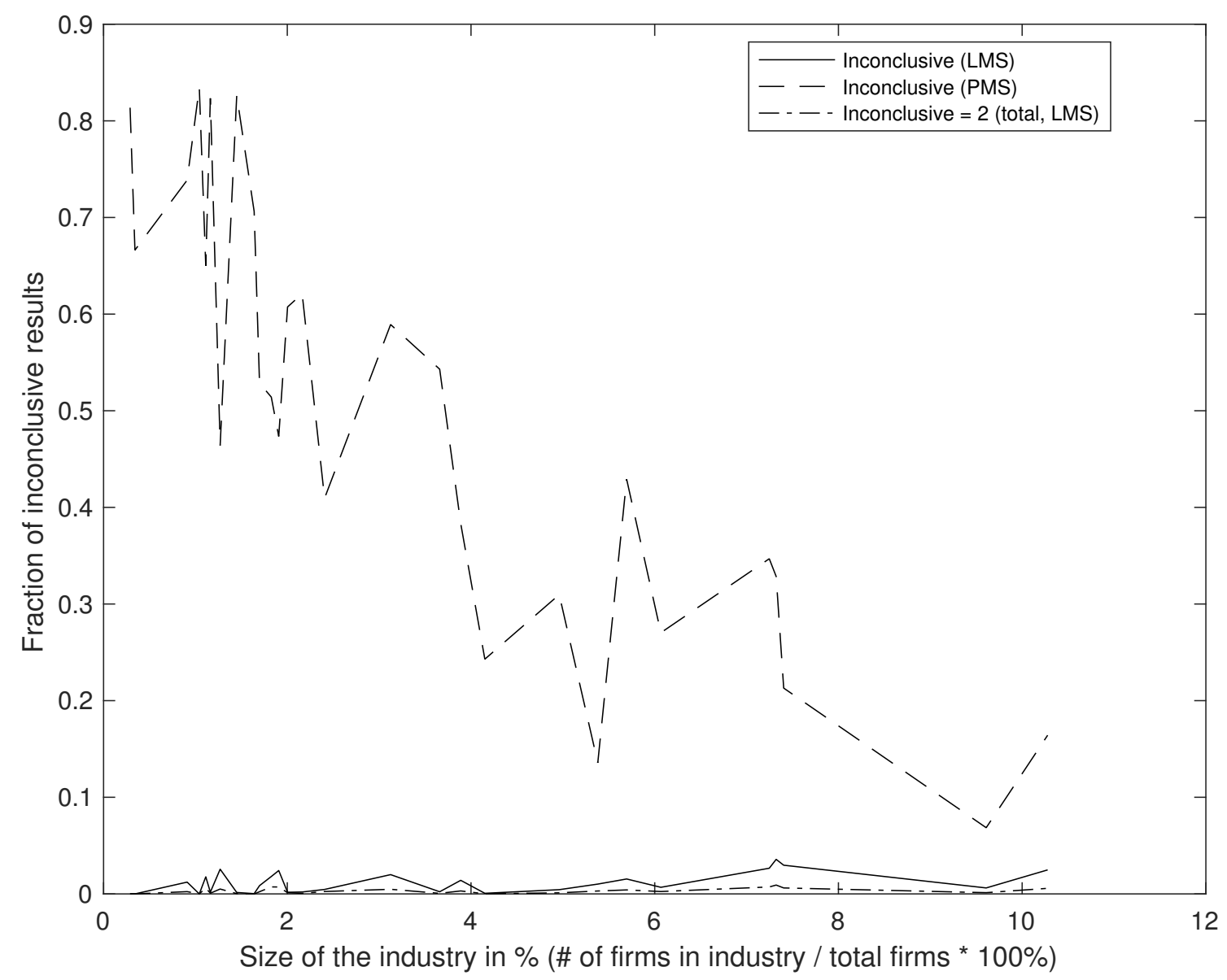

The relationship between conditional inconclusiveness and industry size is shown for the subset of inconclusive cases between two or three regimes. Conditional inconclusiveness is defined as inconclusiveness based on PMS $(L M S)$ conditional on being conclusive on $L M S(P M S)$. When we restrict the conditional inconclusiveness to two regimes, we only show conditional inconclusiveness for the $L M S$, as for the $P M S$ it is identical to the unrestricted conditional inconclusiveness. 